University of Louisville ThinkIR: The University of Louisville's Institutional Repository

Electronic Theses and Dissertations

$5-2019$

\title{
Marginal staining between pressed lithium disilicate ceramic crowns and direct restorative materials by various fluids : a microleakage study.
}

Sarah Ann Jestel

University of Louisville

Follow this and additional works at: https://ir.library.louisville.edu/etd

Part of the Dental Materials Commons

\section{Recommended Citation}

Jestel, Sarah Ann, "Marginal staining between pressed lithium disilicate ceramic crowns and direct restorative materials by various fluids : a microleakage study." (2019). Electronic Theses and Dissertations. Paper 3235.

https://doi.org/10.18297/etd/3235

This Master's Thesis is brought to you for free and open access by ThinkIR: The University of Louisville's Institutional Repository. It has been accepted for inclusion in Electronic Theses and Dissertations by an authorized administrator of ThinkIR: The University of Louisville's Institutional Repository. This title appears here courtesy of the author, who has retained all other copyrights. For more information, please contact thinkir@louisville.edu. 


\title{
MARGINAL STAINING BETWEEN PRESSED LITHIUM DISILICATE CERAMIC CROWNS AND DIRECT RESTORATIVE MATERIALS BY VARIOUS FLUIDS: \\ A MICROLEAKAGE STUDY
}

\author{
By \\ Sarah Ann Jestel \\ B.S., University of Georgia, 2014

\begin{abstract}
A Thesis
Submitted to the Faculty of the School of Dentistry of the University of Louisville in Partial Fulfillment of the Requirements for the Degree of
\end{abstract} \\ Master of Science \\ in Oral Biology \\ University of Louisville \\ Louisville, Kentucky
}

May 2019 



\section{MARGINAL STAINING BETWEEN PRESSED LITHIUM DISILICATE CERAMIC CROWNS AND DIRECT RESTORATIVE MATERIALS BY VARIOUS FLUIDS: \\ A MICROLEAKAGE STUDY}

$$
\text { By }
$$

Sarah Ann Jestel

B.S., University of Georgia, 2014

A Thesis Approved on

26 March 2019

by the following Thesis Committee:

Michael J. Metz, DMD, MSD, MS, PhD

Thesis Director

Marcelo Durski, DDS, MDS, PhD

Gary Crim, DMD, MSD

Cynthia Metz, PhD 


\section{DEDICATION}

This thesis is dedicated to my parents

Timothy and Susan Jestel

and

Dr. Michael Metz

who has provided an invaluable education opportunity

and wonderful mentorship over the last four years. 


\section{ACKNOWLEDGEMENTS}

I would like to thank my thesis director, Dr. Michael Metz, for his guidance and patience throughout this process. I would also like to thank the other committee members, Dr. Marcelo Durski, Dr. Gary Crim, and Dr. Cynthia Metz, for their comments and assistance over the past four years. Thank you to Dr. Douglas Darling, who provided research design assistance in the first year of this program. To my mom and dad, Tim and Susi Jestel, and my fiancé, Jordan Key, thank you for providing encouragement and support throughout this long process. You are the reason this thesis came to fruition.

Funding for this research was provided by the University of Louisville Summer Research Program in 2016 and 2017; thank you, Dr. Donald Demuth, for giving students both experiential and financial support to explore research opportunities while in dental professional programs. Additional funding for this research was provided by the University of Louisville Faculty Research Grant in 2017; thank you for providing the funding needed for digital impressions and fabrication of all the IPS e.max crowns needed in the study. To Roy Dental Labs, thank you for your efficient and exceptional

work in making all 80 indirect restorations for this research. And finally, to the Indiana University School of Dentistry, thank you for the use of your Instron cyclic uniaxial loader, thermocycler, diamond saw, and stereomicroscopy (50X) instruments. 


\title{
ABSTRACT \\ MARGINAL STAINING BETWEEN PRESSED LITHIUM DISILICATE CERAMIC CROWNS AND DIRECT RESTORATIVE MATERIALS BY VARIOUS FLUIDS: A MICROLEAKAGE STUDY
}

\author{
Sarah Ann Jestel
}

26 March 2019

\begin{abstract}
When treating patients with existing restorations in which indirect restoration
\end{abstract} placement is indicated and crown lengthening surgery is contraindicated, dentists may choose to finish the crown margin on an existing restoration. The interface between the two dental restorations (resin composite and ceramic crown) may be more susceptible to microleakage and fluid staining, reducing restoration longevity. In this study, 80 extracted molars received indirect restoration margins finished on different direct restorative materials (resin-modified glass ionomer and conventional, flowable, and bulk fill nano-hybrid resin composite) and subjected to common staining fluids of coffee, tea, red wine, or Coca-Cola. If the clinician must finish lithium disilicate all-ceramic crowns on a direct restorative material, conventional or bulk fill nano-hybrid resin composite or resin-modified glass ionomer materials are better choices than a flowable nano-hybrid resin composite, regardless of common fluids consumed by the patient. 
TABLE OF CONTENTS

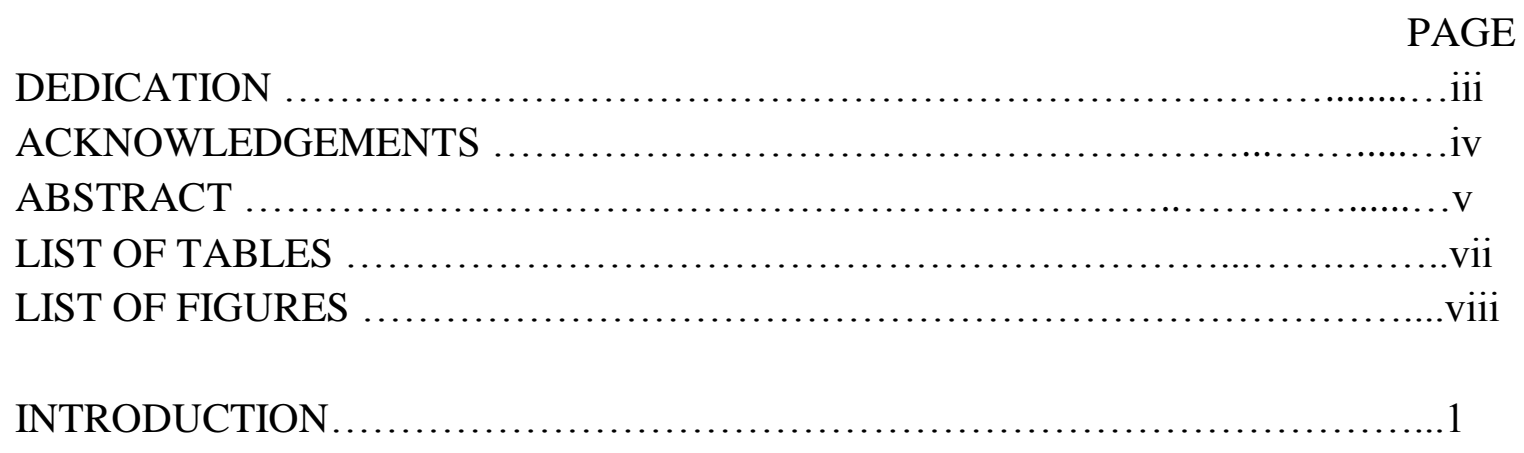

SPECIFIC AIMS AND HYPOTHESES .....................................24

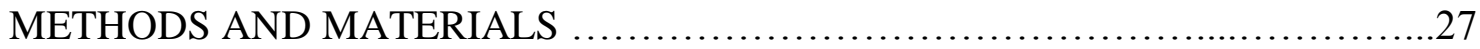

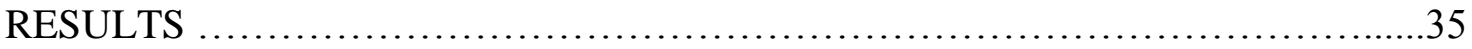

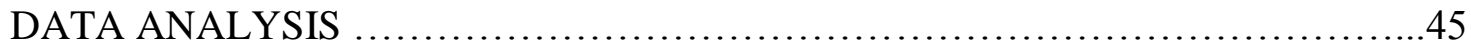

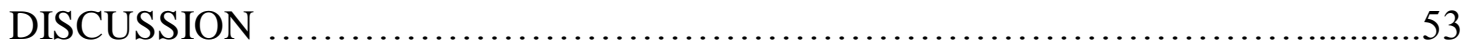

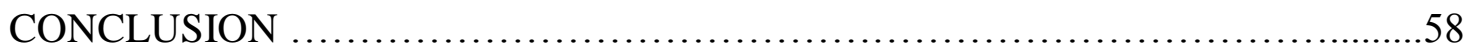

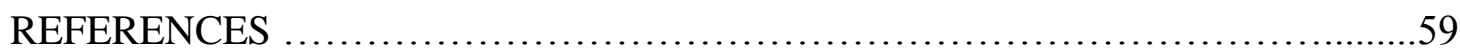

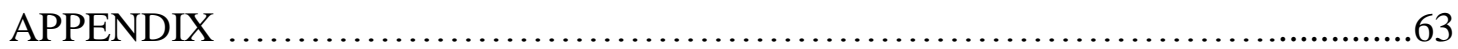

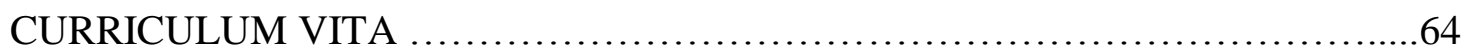




\section{LIST OF TABLES}

TABLE

PAGE

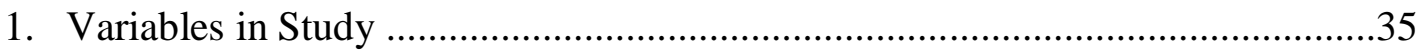

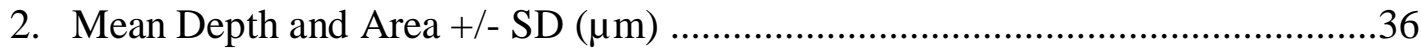

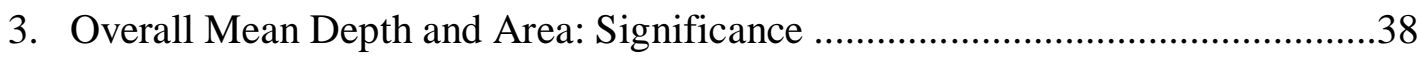

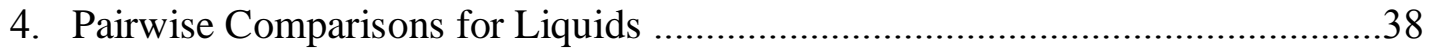

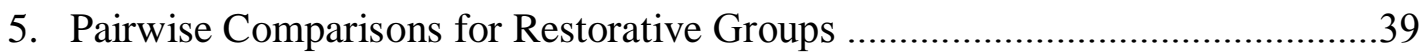




\section{LIST OF FIGURES}

FIGURE

PAGE

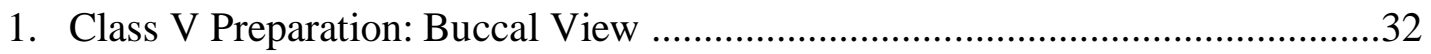

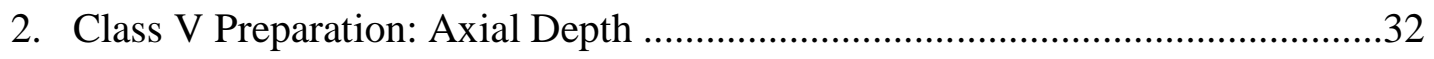

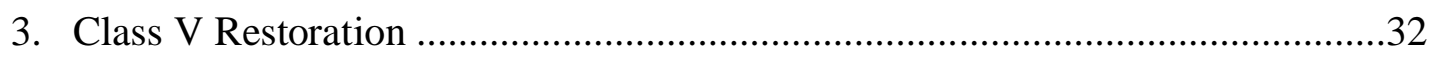

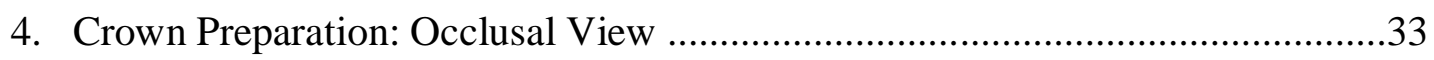

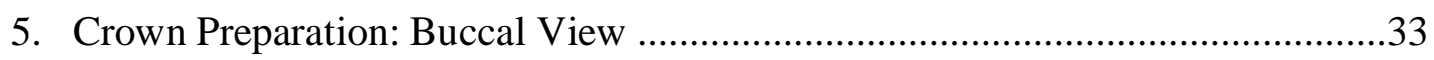

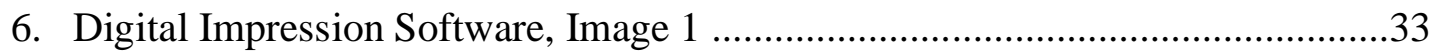

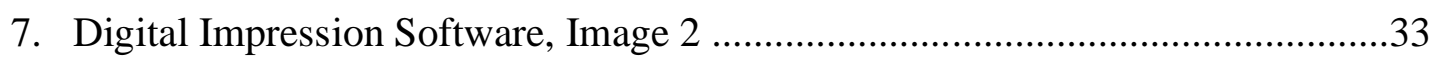

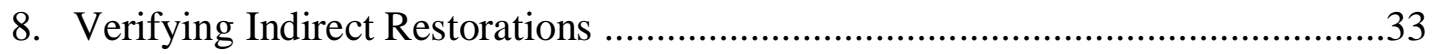

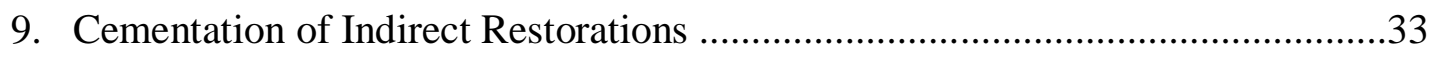

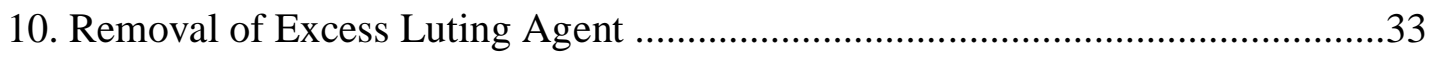

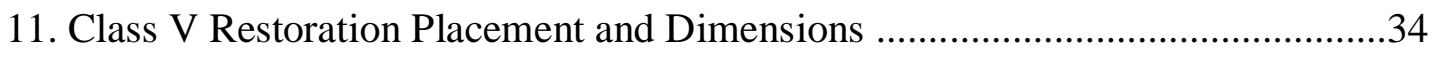

12. Treatment and Control Sides and Margin Finish Line Placement for Lithium

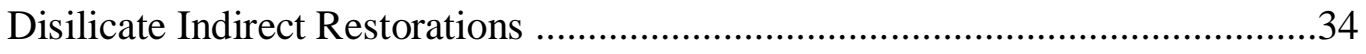

13. Microleakage Depth (microns) for Liquid Media Groups ...............................43

14. Microleakage Depth (microns) for Restorative Material Groups .....................43

15. Microleakage Area (microns) for Liquid Media Groups ...............................44

16. Microleakage Area (microns) for Restorative Material Groups ........................44 


\section{INTRODUCTION}

Clinical scenarios exist in which patients have an existing Class V direct restoration at or below the CEJ, an indication for indirect restoration placement, and a contraindication for crown lengthening surgery. This could be the case in a tooth with compromised width of keratinized tissue or furcation involvement, in which crown lengthening would cause impingement on the biologic width, increased crown to root ratio, and decreased stability. It is important to achieve optimal bond strength when luting indirect restorations, as this will decrease microleakage, recurrent caries, dentin hypersensitivity, and marginal staining that could occur at the interface of the indirect restoration and the tooth. As a next-best alternative, dentists may choose to place the margin of the crown on the existing restoration. The interface between the two dental restorations (resin composite and ceramic crown) may be more susceptible to microleakage and fluid staining, reducing restoration longevity (as compared to bonding between dental tissue and indirect restorations). There have been limited publications regarding nano-hybrid flowable resin composites/finished crown margins, and no published research study has analyzed microleakage of common fluids in margins of these restorations.

This literature review will analyze the materials, concepts, and instruments used in the research study, including flowable resin composite, conventional resin composite, bulk fill resin composite, resin-modified glass ionomer, pressed lithium disilicate ceramic indirect restorations, bonding and luting agents, microleakage, digital scanning, Instron 
testing, thermocycling, and stereomicroscopy.

Flowable resin composite materials have been available to dental practitioners since late in 1996 and were introduced in order to better adapt to narrow cavity walls than other 'putty-like' direct restorative materials (1). There are several different kinds of flowable resin composites. The flowable resin composite used at the University of Louisville School of Dentistry is an Ivoclar product by the name of Tetric EvoFlow. This flowable composite material has 'optimum coordination with Tetric EvoCeram shades' (2), meaning it can be shade matched and combined with conventional resin composite for a more ideal restorative result. Once practitioners understand the properties of flowable composite, they can make evidence-based decisions for use in clinical situations.

All composite dental materials have two major components: filler particles (for fracture resistance and mechanical properties) and resin matrix (flowability). Flowable composites have lower filler: matrix ratio than conventional composites (reduced from $50-70 \%$ to $37-53 \%$ filler volume) (1). The Ivoclar Tetric EvoFlow resin composite composition fits within the accepted percentages for flowable composite (37.6\% BisGMA, Urethane dimethacrylate, and decandioldimethacrylate (resin matrix), $41.1 \%$ barium glass filler, ytterbiumtrifluoride, mixed oxide, highly dispersed silica (filler)) (2). The reduced filler: matrix ratio makes flowable resin composites 'ideal for use in small preparations that would be difficult to fill otherwise' (1).

However, flowability of Tetric EvoFlow and other flowable resin composites comes at a price. When strength and fracture toughness are taken into account, multiple studies analyzed indicate decreased ability to resist fracture. Bayne et. al. indicate mechanical properties of 60-90\% those of conventional resin composite strengths, Nuray et. al. 
conclude significantly lower flexural strength for flowable composites when compared with conventional composites, and Burke et. al. report marginal fracture (18\%) and bulk fracture $(7 \%)$ as the two largest reasons for failure in flowable composites $(2,3,4)$. There is significantly lower wear resistance when exposed to function and chemical abrasion due to the decreased amount of filler. Ivoclar's measurements for EvoFlow are consistent with the findings above. Both the Vickers hardness of $320 \mathrm{MPa}$ (compared to $580 \mathrm{MPa}$ in conventional resin composites) and the flexural strength of $114 \mathrm{MPa}$ (compared to 120 $\mathrm{MPa}$ in conventional resin composites) are lower than Ivoclar's conventional resin composite (2). This decrease in fracture resistance and flexural strength compound other inherent challenges in using flowable composite materials.

Most dental resin composites must be light-cured when they are placed in preparations (core build-up materials may be light-cured, self-cured, or dual-cured). The high molecular weight dimethacrylate resins undergo addition polymerization and shrink in overall volume as the bonds between the polymer chains are formed $(1,2)$. In a study by Toshiki et. al., this shrinkage in flowable resin composites was found to be greater than in conventional resin composites, resulting in decreased modulus of elasticity and flexural strength (6). The results of this shrinkage can lead to lack of adhesion on the wall; as resins pull away from the wall, marginal integrity suffers. Microleakage can result, which is defined as 'a clinically undetectable movement of bacterial fluids, molecules, and ions in microgaps $(10-6 \mu \mathrm{M})$ between the cavity wall and the restorative materials applied to it' (7). These gaps could have resulted from an initial defective margin (polymerization shrinkage falls into this category) or degradation of the tooth wall-restorative material interface over time (8). One of the most common reasons for this degradation is due to 
polymerization shrinkage and subsequent stress on the bonding agent adhesive; Tjäderhane attributes this adhesive failure phenomenon to 'hydrolytic or mechanical breakdown or enzymatic degradation of the resin material or the bonding layer' (9). This breakdown results in a decreased seal between the restoration and the enamel or dentin, leading to microgaps (8). The oral environment can also cause degradation. Plaque formation, oral biofilm, acid erosion, abrasion, or attrition can exacerbate any initial microgap formation and jeopardize the cavosurface margin integrity over time. In a research study conducted by Ivana Nedeljkovic et. al., these oral factors are cited as playing a more significant role in composite failure through secondary caries than any inherent material property (including polymerization shrinkage, cariogenic bacteria adhesion on the composite surface, and lack of antibacterial activity) (10). In any case, tooth demineralization may occur as microleakage occurs. J.L. Ferracane describes this direct relationship by stating 'tooth demineralization has been attributed to leakage of either bacteria or their acid by-products within this gap, termed microleakage' (8). When this microleakage occurs, pulpal pathology, secondary carious lesions, post-operative pain, and sensitivity may result (1). Carlos José Soares et. al. and Tantbirojn et. al. include a visual of these negative results in their journal article, which can be seen in the appendix (11).

Although increased marginal microleakage is not ideal, Ivoclar products shrink less than other flowable resin composites. According to a study completed by Dr. David Watts, polymerization shrinkage measured in percent volume was just over $4 \%$, as compared to X-flow, which had a polymerization shrinkage of 6\% (2). Regardless of the type of flowable composite used, additional properties of flowable resin composite 
compared to conventional resin composites may lead to problematic restorations. These include increased translucency, decreased color stability, and decreased biocompatibility (due to increased exothermic reaction and increased BisGMA release) (1). While these properties are not ideal, especially when compared to conventional composites, it is important to understand limitations of use before indications for use are explained.

While the risks outlined above limit flowable resin composite as a restorative material, there are specific indications for use. The systematic review published by Baroudi and Rodrigues gives several indications: preventive resin restorations (Class 1, minimally invasive), pit and fissure sealants, cavity liners, Class II restorations (minimally invasive and sealing gingival margins of inner layers), and Class $V$ abfractive lesions (1). All of these indications place a higher emphasis on adaptation to the preparation and/or flexure of the restoration than strength of the restoration. There are other less common indications for flowable composite given in the review, including orthodontic, posttrauma/emergency repairs, repair of previous restorations, luting, and bonding fiber posts (1). As long as the flowable composite is not used in load-bearing areas, the flowable composite is a good material for repair and bonding. Ivoclar's recommendations are on par with the study above, stating EvoFlow should be used for 'restoration of cervical defects, micro-cavities, extended fissures, [and] ... initial layer in large Class I and Class II cavities, as they more easily adapt to the cavity' (2). Flowable resin composites are appropriate restorative materials in direct restorations, as long as the practitioner follows indications for use outlined by manufacturers and evidence-based dentistry.

Conventional resin composites differ from flowable resin composites in that there is a higher ratio of filler to matrix content within each material. Conventional composite 
materials have approximately $75-80 \%$ filler content by weight (12). The Tetric EvoCeram fits within this classification system, with a composition consisting of dimethacrylate monomer matrix (17-18\% weight), filler of barium glass, ytterbium trifluoride, mixed oxide and pre-polymer (82-83\% weight), and additives, catalysts, stabilizers and pigments $(<1.0 \%$ weight $)(13)$. With this increased filler content, the mechanical properties of the material changes. Conventional composites are more appropriate than flowable composites for load bearing restorations, because the increased filler content increases wear resistance and fracture toughness.

Other conventional composite indications for use include: 'Class I, II, III, IV, V, and VI restorations, foundations or core buildups, sealants and preventive resin restorations (conservative composite restorations), esthetic enhancement procedures, partial and full veneers, tooth contour modifications, diastema closures, cements (for indirect restorations), temporary restorations, and periodontal splinting (12). Ivoclar's indications for use of Tetric EvoCeram correspond with the aforementioned list: 'Restoration of deciduous teeth, the posterior region (Classes I and II), anterior restorations (Classes III, IV), Class V restorations (cervical caries, root erosion, wedge-shaped defects), veneering of discolored anterior teeth, splinting of mobile teeth, extended fissure sealing in molars and premolars, repair of composite/ceramic veneers, and build-ups for transparent, removable, Invisalign ${ }^{\circledR}$ orthodontic retainers.' The contraindications of inadequate isolation, locations with heavy occlusal stress, and allergic reactions mirror those of flowable composite $(12,13)$.

Conventional composite has been well documented in literature as an appropriate tooth replacement material, as long as the practitioner understands the mechanical 
properties and limitations for use. Composite materials are esthetic, conservative, used universally, retentive, repairable, and not thermally conductive (12). However, composite materials have significant disadvantages as well. Increased polymerization shrinkage, placement technique sensitivity, occlusal wear, poor linear coefficient of thermal expansion, and potential microgap formation can all limit the longevity of composite restorations (12). These disadvantages must be weighed against the advantages when deciding which dental materials to use.

Photo-polymerization of light-cured resin composites hardens the material within the cavity preparation. Depending on the type of composite, there are different photoinitiator systems to activate polymerization within the material. A review of resins used for dental composites conducted by A.P.P. Fugolin and C.S. Pfeifer describes the Ivocerin photoinitiator system used in Tetric EvoCeram. This 'germanium-based light initiator provides greater quantum yield conversion and more efficient polymerization in depth, reducing shrinkage and stress, especially when combined with EvoCeram products' prepolymerized resin filler particles' (14). This photoinitiator was further tested in studies by Jang et al., whose study in 2015 confirmed low shrinkage stress and efficient depth of cure (15) of Ivoclar composite products. It is important that correct technique for placement and use of materials, including the composite material and any curing lights, are optimized for best curing potential.

Placement technique of most resin composite restorations is optimized if the practitioner places and cures resin composite in $\leq 2 \mathrm{~mm}$ increments and cone-shaped additions rather than flat layers (segmental/cross-hatch technique). This segmental/crosshatch technique is advantageous over a horizontal layering technique, as each layer's 
polymerization shrinkage affects a smaller number of internal and external walls in the cavity preparation. Additionally, any new composite increments may compensate for the shrinkage of the deeper layers. In a Class V cavity preparation, a horizontal layering technique may touch five different preparation walls: axial-incisal, axial-gingival, axialmesial, axial-distal, and pulpal walls. Polymerization shrinkage will occur, resulting in potential microleakage around the entire margin of the restoration. The segmental/crosshatch technique, in contrast, may have layers touching three to four walls in a coneshape, followed by other composite increments layered on top to compensate for the shrinkage of the lower layers. This may reduce both microleakage and any secondary factors limiting longevity of the restoration (ex: caries, demineralization, etc.). This technique is still considered the gold standard, especially in conventional and flowable resin composite materials. However, dental practitioners desire increased procedure efficiency, while not compromising the properties of the restorative result. The solution to this challenge may be found in bulk fill resin composites.

Bulk fill resin composites are opposite flowable resin composites and have a higher ratio of filler particles to resin matrix than both flowable resin composites and conventional resin composites. This class of composite materials has been marketed as an alternative to traditional resin composites, which require increased technique sensitivity and time. The increased filler content theoretically allows the practitioner to place up to 4 $\mathrm{mm}$ of bulk fill material per layer of curing, in an effort to decrease the time and difficulty required for restorative procedures. This form of composite was created in a response to practitioners who desired faster procedure times in placing direct restorations. Ivoclar's bulk fill nano-hybrid resin composite, Tetric EvoCeram Bulk Fill, markets the 
product as having the following advantages: 'Increments of up to $4 \mathrm{~mm}$, dentin-like or enamel-like volume replacement, 10 seconds [curing] (>1000 mW/cm2), time savings of $47 \%$ compared to the conventional technique, and chameleon effect ensures a natural shade blend' (16). Although these advantages sound ideal for improving procedure speed and efficiency, it is important to note that curing depth is reliant upon the shade, depth, and translucency of material. Restorations with shallower material depths, lighter shades, and more translucent materials can achieve a more complete cure with the same curing light than corresponding restorations with deeper material depth, darker shades, and less translucent materials. It is very important to have a 'complete cure, as uncured resin remaining at the base of the preparation can result in post-operative sensitivity, marginal leakage, caries, and mechanical fracture of the restoration' (17). Knowledge of curing process is essential for longevity of results and patient satisfaction, especially for these bulk fill resin restorations. It may be important for the practitioner to use less resin material or cure more often with deeper curing depths or darker restorative shades.

The Ivoclar Tetric EvoCeram Bulk Fill resin composite composition fits within the accepted percentages for bulk fill composite of 'monomer matrix of dimethacrylates (2021 wt.\%), filler of barium glass, ytterbium trifluoride, mixed oxide and copolymers (79$81 \mathrm{wt. \%})$, additives, initiators, stabilizers and pigments (<1.0 wt.\%) (16). This type of bulk fill resin composite is classified as a bulk fill high viscosity RBC, requiring light cure and maximum depth $4 \mathrm{~mm}$ per increment, with no need for conventional RBC capping layer, according to a review paper completed by J. Chesterman et. al. Other types of bulk fill composites are bulk fill base RBC (low viscosity), sonic-activated bulk fill RBC (flowable under sonic energy, harden to allow molding and carving), and dual-cure 
bulk fill RBC (medium viscosity with any depth incremental placement) (17). These various types of bulk fill resin composite have different techniques for placement; it is important that the clinician reads the manufacturers' recommendations, as some may suggest bulk fill base use only (recommend covering the bulk fill material with a conventional $\mathrm{RBC}$ ) or proximal and occlusal contact surface restorations in conventional RBC. Additionally, esthetics may dictate need for capping with conventional hybrid $\mathrm{RBC}$, as bulk fill resin composites typically have a less esthetic appearance (17).

Even if the technique and curing protocols are adhered to, polymerization shrinkage and marginal gaps may still result. Any resin increment which touches more than one wall of the preparation 'increases the $\mathrm{C}$-factor. The shrinkage stress can lead to failure of the restoration at the weakest interface which is between the tooth and restorative material. This in turn can result in a number of potential problems including secondary caries, marginal staining, tooth fracture, and post-operative sensitivity’ (17). Chestman uses $\mathrm{C}$-factor to describe microgap formation and marginal microleakage, with the same negative potential results as described in flowable resin composites placed with a horizontal layering technique as compared to the segmental/cross-hatch technique. In vitro studies show less shrinkage of these materials as compared to other resin restorative materials, but any uncured resin may still result in negative effects. Because bulk fill resin composite materials are relatively new, marginal gap formation evidence is not conclusive at this time with respect to bulk fill resin composites verses traditional resin composites (17). However, any polymerization shrinkage may lead to a marginal void. Superior placement technique, such as consideration of curing depth, segmental/cross- 
hatch increments, and proper isolation are essential to improving the longevity and quality of the restoration.

Indications for use of bulk fill composites are similar to conventional resin composites. Ivoclar's Tetric EvoCeram Bulk Fill resin composite indications for use are as follows: restorations in 'deciduous teeth, Classes I and II (including cuspal restorations), Class V restorations, reconstructive build-ups, and extended fissure sealing in molars and premolars' with contraindications in patients with 'isolation or technique problems or allergies to ingredients in the composite material' (16). Although bulk fill is accepted as an indication for use in Class V restorations, each clinical situation needs to be evaluated carefully. A conventional composite (which may be more esthetic) or a resin-modified glass ionomer (which releases fluoride) or might be more appropriate.

Resin-modified glass ionomer direct restorative materials were introduced for dental clinical use in 1991 (18). These materials consist of two major components: resin composite and glass ionomer. Glass ionomer is a dental restorative material consisting of 'three essential ingredients, namely polymeric water-soluble acid, basic (ion-leachable) glass, and water (18). Glass ionomer restorations are advantageous due to fluoride release, resulting in a decrease in recurrent caries. This is especially important for patients with high caries rate and/or cervical, or root, caries (12). While this fluoride release is advantageous, it also decreases the strength and esthetics of glass ionomer restorations. This is another reason cervical preparations (non-load bearing areas) are a great location for glass ionomer materials. Resin-modified glass ionomer materials possess the best of both resin composite and glass ionomer materials: RMGI have both fluoride release and improved esthetic and mechanical properties (12). In addition to 
cervical carious locations, Sturdevant sites the following clinical situations as ideal indications for RMGI: 'slot-like preparations in Class II or III cervical locations without a proximal contact or cervical erosion/abrasion/abfractive lesions' (12). Because RMGI has greater flexural strength than composites, the material will accommodate any flexing of the tooth in the cervical third better than their composite counterparts. RMGI are also able to be 'recharged,' meaning any topical fluoride applied to restorations after placement will take in new fluoride for future release. RMGI materials use a different type of etchant than composite restorations. Composite materials are generally etched with $37 \%$ phosphoric acid, whereas glass ionomer materials are etched with 10-20\% polyacrylic acid, and not all GI materials require etch (12). This etchant is more compatible with glass ionomer materials.

GC America produces a light-cured RMGI material called Fuji II LC and a self-cured glass ionomer material called Fuji IX. Fuji II LC is indicated for use in 'Class III and V restorations, cervical erosions, root surface lesions, pediatric restorations, and base or liner (sandwich technique)' restorative situations (19). Fuji IX is a 'packable posterior self-curing restorative material' used in 'Class I and II restorations (non-stress bearing), Core build-ups, Pediatric / geriatric restorations, Base or liner (sandwich technique) situations, intermediate restorative, and long-term temporization' clinical scenarios (19). These indications correspond with Sturdevant's recommendations for use. These materials have been well documented in literature as retentive, successful materials in cervical lesions (20), and thus, it would not be unreasonable to find class V RMGI or GI restorations in patients. In this study, Fuji II LC was used in order to approximate the mechanical properties of the other three composite materials. 
Bonding agents are essential in the longevity of composite restorations. A bonding agent provides the adhesive between enamel and dentin and restorative materials. When a preparation is completed, the surface of the tooth become filled with a $1.0 \mu \mathrm{m}$ layer of cutting debris from dental handpiece use, called the smear layer. The smear layer penetrates the tubules and produces 'smear plugs,' a physical barrier to bonding which can reduce dentin permeability by $86 \%$ (21). Both this smear layer and corresponding smear plugs may be removed or modified in order for composite restorations to be retentive. An etch agent, typically $37 \%$ phosphoric acid for composite materials or 10 $20 \%$ polyacrylic acid for glass ionomer materials, is used to remove this layer and open the dental tubules. A cavity conditioner (etchant) may be used at this time to further clean the dental tubules. Additionally, chlorhexidine gluconate solution, a disinfectant, may be used to enhance the longevity of bonding agents. Regardless of materials used, it is important not to dehydrate the tubules through excessive drying, as this could cause collapse of the dental collagen and fewer available tubules for which the primer and bonding agents can interlock. The dental tubules are hydrophilic, and thus, the hydrophobic components in the dental restorative materials will not achieve as optimal a seal without a primer and bonding agent. When a hydrophilic primer is added to the etched dentin or enamel layer, prism-like 'resin tags' are able to flow into the dentin tubules and increase wettability of the surface, thus providing a mechanical lock of the bonding agent into the dentin. The hydrophobic bonding agent is then added to the preparation. This bonding agent connects the hydrophilic primer to the hydrophobic dental restorative material. The complete primer/bonding layer within the preparation is called the hybrid layer, first coined by Nakabayashi in 1982 (21). This process provides 
the foundation for adhesive dentistry and is essential in decreasing microleakage and increasing longevity of composite restorations.

Bonding agents have come a long way since 1955, when Buonocore introduced adhesive dentistry (21). Bonding agents are classified by type of etch and number of steps involved in the adhesive process. The first three generations of bonding agents did not completely remove the smear layer, resulting in a poor bonding seal. Total etch systems began with the fourth-generation bonding agents. These three step systems require a separate etch, primer, and bonding agent, and are still considered the gold standard in dentinal bonding with a bond strength of $\sim 20$ MPA (21). Fifth generation bonding agents, introduced in the 1990's, are a two-step process, in which an etch and primer/bond combination are used. These agents combined the hydrophilic and hydrophobic agents into a single 'bonding agent' solution. Although this helps prevent collagen collapse and post-operative sensitivity and has less technique sensitivity and time required, water degradation may occur more readily in these fifth-generation bonding agents. Dentin bond strength in these materials have an increased range, 3 to $25 \mathrm{MPa}$ (21). Total etch bonding systems remove the smear layer and smear plugs so that resin tags from the bonding agent may flow into the dentin tubules, producing a stronger bond. However, there is a potential for higher sensitivity due to fluid movement within the tubules, according to the hydrodynamic theory (12). The bonding agent used in this study, ExciTE $\mathrm{F}$, is a fifth-generation bonding agent. This generation of bonding agent and all generations since the fifth have developed in response to practitioner's demand for decreased procedure technique sensitivity and time required. 
The self-etch systems consist of generations 6,7 , and 8 . The self-etch systems do not dissolve and wash away the smear layer, as is the case with the total etch systems. Selfetch systems contain 'various acidic primers used to modify, disrupt, and/or solubilize the smear layer and, although the remnants are not washed away as with total-etch systems, still permit direct adhesive interaction with the dentin substrate' (21). These self-etch systems do not provide as strong a bond as the total etch systems, but still provide an interlocked mechanical layer between the dental tissue and the restorative material by incorporating the smear layer into the mechanical bond. Sixth-generation bonding agents mix an acidic primer and an adhesive just prior to use, so that the etch, hydrophobic, and hydrophilic components are combined in one solution. These bonding systems decrease emphasis on the hydration of the dental tissue, which is an advancement when comparing fifth and sixth generation bonding agents. However, bonding to enamel may suffer, as combining the acid etch with other components lessens its impact. Some report the enamel bond as $25 \%$ weaker in sixth-generation agents than total etch agents (21). Seventh-generation bonding agents combine all components into a single bottle. Although clinicians may gain efficiency in technique and placement by using this generation, the components favor a hydrophilic environment, which produces a weak bonding environment. Disadvantages include 'more prone to water sorption, limited depth of resin infiltration into the tooth with resulting potential voids, and adverse reactions with composite initiator systems' (21). Eighth-generation bonding agents, produced by voco America in 2010, are the newest generation on the market today. These bonding agents contain nano-fillers to increase penetration of resin monomers, hybrid layer thickness, and mechanical properties. Although in vitro studies gave higher bond 
strength for this generation, more research is needed for these bonding agents, which have the potential to accumulate filler on a moistened surface, induce cracks, and decrease bond strength (21). Bonding agents provide longevity of adhesive restorations, as well as the 'ability to decrease or eliminate postoperative sensitivity, improve marginal seal, reduce microleakage and enhance the flow of resin into fissure' (21). Any microleakage occurring as a result of polymerization shrinkage may result due to a failure of the bonding agent. It is important to have a firm foundation in direct restorations and phase 1 dentistry prior to any phase two dentistry, which includes crown preparation, impressions, and indirect fabrication of fixed and removable restorations.

Digital scanning is becoming increasingly more popular in dental labs and offices across the country. The use of these scanners expedites fixed partial denture impressions and minimizes translation errors in impression materials and lab work completed prior to FPD fabrication. The scanner used in this experiment uses 'new multi-line blue LED technology ... [and] allows you to scan single dies directly on the model ... made possible by the unit's four high-resolution 5MP cameras' (22). This study used a Weiland D1000 scanner to create digital impressions of the teeth specimen. Sending the dental samples allowed for faster processing and potentially closer marginal adaptation of the crowns to the teeth than traditional impression materials. One advantage of the scanners is the ability to design the indirect restoration immediately after imaging. The associated software allows the user to ensure the scanner accurately captured the crown preparation and correct any contour, contact, occlusal, marginal, or other potential problems prior to fabrication. In this experiment, marginal adaptation was the most important parameter. All margins were checked in the software prior to fabricating the indirect restorations. 
Digital scanning technology has improved since initially coming to the market, but there is still some question as to whether digital or conventional impressions is more accurate. A systematic review and meta-analysis published in the Journal of Prosthetic Dentistry addressed ceramic crowns impression accuracy. The 12 studies included in the meta-analysis were split into in vivo and in vitro studies: the in vivo studies had a 'mean marginal discrepancy of the restorations after the digital impressions [of] $56.1 \mu \mathrm{m}(95 \%$ CI: 46.3-65.8 $\mu \mathrm{m})$, whereas after conventional impressions $79.2 \mu \mathrm{m}$ (95\% CI: 59.6$98.9 \mu \mathrm{m})$ ' and the in vitro studies had 'the mean value of the marginal fit was $58.9 \mu \mathrm{m}$ (95\% CI: 41.1-76.7 $\mu \mathrm{m}$ ), whereas after digital impressions it was $63.3 \mu \mathrm{m}$ (95\% CI: 50.5$76.0 \mu \mathrm{m})$ ' (23). Both the in vivo and the in vitro marginal discrepancies between the conventional and digital technological techniques were statistically insignificant. The study concluded 'no significant difference was found regarding the marginal discrepancy of single unit ceramic restorations fabricated after digital and conventional impressions' (23). In another study published in the Journal of Prosthetic Dentistry, marginal and internal fit of lithium disilicate inlays was evaluated from three different techniques: milling, 3D printing, and conventional technologies. The five test groups were conventional impression/manual wax pattern, conventional impression/lab scanning of stone die/CAD-CAM milling, conventional impression/lab scanning of stone die/3D printing wax pattern, digital impression/CAD-CAM milling, and digital impression/3D printing. The results of the study indicated 'lithium disilicate glass-ceramic inlays produced from digital impressions and subtractive milling of wax patterns resulted in better marginal and internal fit accuracy than either conventional impression/fabrication or additive 3D manufacturing' (24). Although the study analyzed both processing and 
scanning of the ceramic crowns, it is important to note digital impressions yielded better results when combined with superior processing techniques than conventional impression and processing techniques.

Lithium Disilicate, or IPS e.max press, is a glass ceramic material available to practitioners as they design crowns for patients. Lithium disilicate can be pressed and contoured into indirect restorations via the lost wax burnout technique and ceramic layering by a dental laboratory technician $(25,26)$. Because this is a relatively new material when compared to porcelain fused to metal restorations, the longevity of lithium disilicate restorations has been extensively reviewed. In a systematic review completed by Sascha Pieger et. al. and published in the Journal of Prosthetic Dentistry, twelve studies were reviewed for short-term (1-5 years) and medium-term (5-10 years) survival rates. According to the results of the literature review, 'the 2-year cumulative survival rate for single crowns was $100 \%$, and the 5 -year cumulative survival rate was $97.8 \%$. The 2-year cumulative survival rate for fixed dental prostheses was $83.3 \%$, and the 5 -year cumulative survival rate was $78.1 \%$. The cumulative survival rate over a 10 -year period, primarily owing to data from 1 study, was $96.7 \%$ for single crowns and $70.9 \%$ for fixed dental prostheses' (27). In this study, the medium-term survival rate had less supporting data than the short-term survival, but the single unit restorations did have high longevity rates, especially in the anterior region. This provides supporting data for use of lithium disilicate restorations.

The marginal adaptation of lithium disilicate restorations is also significant within the context of this study. Microleakage will naturally increase if the marginal adaptation is not ideal. Mathieu Contrepois et. al. completed a systematic review of 54 articles in the 
Journal of Prosthetic Dentistry analyzing this marginal adaptation. After analyzing parameters which influence marginal adaptation (finish line conjugation, value of predefined cementing space, veneering process, and cementation), $94.9 \%$ of the gaps measured were within clinical acceptability, or less than $120 \mu \mathrm{m}(28)$. The article sites plaque accumulation and resulting increased risk of carious lesions, microleakage, endodontic inflammation, periodontal disease, and cement dissolution as potential results of poor marginal adaptation. It was concluded that chamfer finish lines yield less marginal discrepancy than straight shoulder margins, but equal or potentially more marginal discrepancy than rounded shoulder margins (28). Cementation was also analyzed: thickness and viscosity of cement may cause more marginal discrepancy than fine-grained cements. The article concluded with the following clinical implications: 'selection of a system should not be based primarily on marginal accuracy, as the marginal adaptation of ceramic crowns from the various systems is generally clinically acceptable, but rather on a system's ability to produce the type of ceramics best adapted to existing clinical conditions and esthetic expectations' (28). Within the context of this study, lithium disilicate single unit indirect restorations have both longevity and marginal adaptation needed for the researchers to confidently choose this material for the study's indirect restorations.

While most of the retention in indirect restorations comes from the design of the preparation, namely taper and a diamond-cut surface, a luting agent serves as the cement between the tooth surface and the intaglio of the indirect restoration. Like bonding agents, different luting agents have different components and techniques. The various luting agents available to practitioners today include zinc phosphate, zinc 
polycarboxylate, glass ionomer, resin-modified glass ionomer, and resin. While zinc phosphate is the standard by which other luting agents are compared, this agent does not bond to the tooth, providing only micromechanical retention. Zinc polycarboxylate was the first luting agent to provide some chemical bonding, but does not have the same longevity as some of the current materials due to plastic deformation and low resistance to acid erosion. Glass ionomer cement was introduced in 1969 as a material with 'ease of mixing, good flow, adhesion to tooth structure and base metals, fluoride release and recharge, good esthetics, adequate strength, and relatively low cost' (29). This material built the foundation for RMGI cements, which add polymerizing resins to traditional glass ionomer cements. This dual-acting system allows for both immediate polymerizing resin bonds and long-acting acid-base glass ionomer action (29). Both RMGI and glass ionomer cements have a chemical bond to the tooth surface. Resin luting agents provide micro-mechanical retention and are split into three different categories: self-cure, lightcure, and dual-cure, which contains both self- and light-cure components. The self- and dual-cure systems are ideal under metal-ceramic indirect restorations, because light penetration is decreased. Light- and dual-cure luting agents are ideal in anterior restorations and veneers, as they allow curing light penetration (29).

In this study, a Multilink Luting agent system was used, which is a primarily selfcuring resin luting agent with an optional light-cure (30). When using the Multilink system, a monobond primer, or a single component bonding agent, is used first to condition the tooth surface. This bonding agent serves the same purpose as the bonding agents previously discussed and falls into the universal adhesive category. These bonding agents do not have as high a bond strength as a total etch system, but still retain micro- 
mechanical retention in the preparation through incorporation of the smear layer into a hybrid layer. The Multilink resin cement is indicated for indirect restorations such as 'Metal and metal-ceramics (PFM), all-ceramics (silicate), reinforced all-ceramics (zirconium and aluminum oxide), and composites and fibre-reinforced composites (FRC)' (30). Vivadent sites e.max pressed lithium disilicate indirect restorations as a primary indication for their Multilink luting agent.

The strength of a luting agent may be increased with additional surface treatments. In addition to conditioning the tooth surface prior to bonding, roughening the intaglio surface of the indirect restoration increases mechanical retention of the luting components. Sandblasting, grinding, and phosphoric acid washes are all ways to physically roughen the surface. Conditioning the intaglio of the indirect restoration with hydrofluoric acid and silane has been shown to significantly increase chemical bonding strength in silicate restorations $(31,32)$. In another study by Hatem M.El-Damanhoury et. al., higher shear bond strength and surface roughness resulted from pre-treatment of the intaglio surface with HF and monobond plus than with monobond etch and primer or monobond plus alone (33). The practitioner should consider using HF to roughen the intaglio surface of their indirect restorations followed by a silane coupling agent to increase bonding strength in indirect restorations.

The Instron material testing system used to simulate chewing forces in the oral cavity evaluates materials for shear strength. The Instron 'shear fixture allows researchers and scientists to evaluate the shear strength of dental materials and adhesives in a controlled in vitro experiment' (34). In this circumstance, the shear strength of the structural adhesive is 'the maximum shear stress in the adhesive prior to failure under torsional 
loading' (35). This testing machine allows variable compressive loads applied at a specific angle to the long axis of the tooth (along the central fossa) to simulate wear the adhesives may be subject to intraorally. In this experiment, the machine was set to $12 \mathrm{~Hz}$ for 10,000 cycles to apply a variable compressive load (40-400 N) in the central fossa, $15^{\circ}$ buccal-lingual to the long axis of the specimens. This is one of the best methods of applying calibrated stress to specimen in vitro, to order to decrease bias amongst the samples. This step can be completed when samples are isolated from the staining fluid, as the decrease in bond strength caused by the Instron testing will allow microleakage by staining fluids in subsequent steps.

A thermocycler is an instrument with broad testing applications, from polymerase chain reaction (PCR) to dental materials testing. With respect to dental materials testing, thermocyclers 'simulate the temperature changes to which the dental materials are subjected in the oral cavity' (36). Temperature changes within the oral cavity are common, as individuals may consume food and beverages of various temperatures throughout the day. The machine itself has 'two large thermostated tanks and one mobile wire basket which dips the samples in one tank and the other alternatively' (36). In this experiment, the samples were subjected to temperature changes from $6-60{ }^{\circ} \mathrm{C}$ for 48 hours, with a 5-minute dwell time in the wire basket between temperature changes in the tanks. This method of testing allowed for staining, as the liquid in the two tanks was the liquid specific to the specimens' staining profile (Coca-Cola, tea, coffee, or red wine). The cycles are executed through software so that 'tanks temperatures, the immersion and emersion speed of the sample, the time in which the basket stays in each tank and in air for drying before being dipped in the next tank' are all standardized amongst the samples 
(36). Immediately after this step, the specimens were sectioned with a diamond saw and water coolant to maintain the staining integrity of the samples and allow visualization of the staining fluid in three 2-mm sections per tooth (three treatment measurements and three control measurements per tooth).

Stereomicroscopy, like thermocycling, is not a concept that is inherent to dental materials testing, nor is it a new concept. This technology, first created by Cherubin d'Orleans in 1671, has evolved into the instruments used today. The stereomicroscopy instruments of today 'feature high numerical aperture objectives that produce high contrast images, which have a minimum amount of flare and geometrical distortion' and come equipped with 'high zoom ratios (up to $12 \mathrm{x}-15 \mathrm{x}$ ) that provide a wide magnification range (between 2x and 540x) and reduce the necessity to change objectives' (37). These microscopes are different from traditional compound light microscopes in that 'a compound microscope provides a single optical path divided at the observation tube to give the same image to both the left and right eye,' whereas a stereomicroscope 'has two different optical paths, or axes, which are offset from one another. The two independent optical systems allow for the depth perception and three-dimensional view that is created by a stereo microscope' (38). The stereomicroscopes have the ability to both magnify and recreate a three-dimensional image, which is ideal for this project. Using this technology at a 50x magnification, the depth and area of stain penetration in $\mu \mathrm{m}$ can be analyzed in a 1 micron boxed dimensional grid to give treatment and control staining values for the samples.

Using the aforementioned materials, concepts, and instruments allowed the researchers to confidently design and execute this research study. 


\section{SPECIFIC AIMS AND HYPOTHESES}

The combination of direct and indirect restoration techniques, dental materials, and analysis methods allow data collection for this study. At the conclusion of the data analysis, the researcher expects to address the following specific aims, research hypotheses, and null hypothesis:

- $\quad$ Specific Aim 1: Is there a difference in microleakage group means, measured as infiltration depth and area in micrometers, when comparing finish lines placed on Class V restorations made with different direct restorative materials (Tetric EvoCeram, Tetric EvoCeram Bulk Fill, Tetric EvoFlow and Fuji II LC) against a positive control for adhesively bonded lithium disilicate crowns subjected to different staining fluids (coffee, tea, red wine, and Coca-Cola)?

- $\quad$ Research Hypothesis: When comparing the microleakage depth and area, it is expected the treatment groups, including Tetric EvoFlow (nano-hybrid flowable resin composite), Tetric EvoCeram (nano-hybrid resin composite), Tetric EvoCeram Bulk Fill (nano-hybrid bulk fill resin composite), and Fuji II LC (resin-modified glass ionomer) will have statistically significant increased microleakage depth and area when compared to the positive control. The null hypothesis for the first research specific aim is that there will be no difference in microleakage depth or area in comparing treatment groups to the positive control. 
- Specific Aim 2: Is there a difference in microleakage group means, measured as infiltration depth and area in micrometers, when comparing finish lines placed on Class V restorations made with different direct restorative materials (Tetric EvoCeram, Tetric EvoCeram Bulk Fill, Tetric EvoFlow and Fuji II LC) against treatment groups for adhesively bonded lithium disilicate crowns subjected to different staining fluids (coffee, tea, red wine, and Coca-Cola)?

- Research Hypothesis: When comparing the microleakage depth and area, it is expected the treatment group 'Tetric EvoFlow' (nano-hybrid flowable resin composite) will have a statistically significant increase in microleakage depth and area when compared to the other treatment groups, including Tetric EvoCeram (nano-hybrid resin composite), Tetric EvoCeram Bulk Fill (nano-hybrid bulk fill resin composite), and Fuji II LC (resin-modified glass ionomer). The null hypothesis for the second research specific aim is that there will be no difference in microleakage depth or area in comparing treatment groups.

- Specific Aim 3: Is there a difference in microleakage group means, measured as infiltration depth and area in micrometers, when comparing finish lines placed on Class V restorations made with different direct restorative materials (Tetric EvoCeram, Tetric EvoCeram Bulk Fill, Tetric EvoFlow and Fuji II LC) against different staining fluids (coffee, tea, red wine, and Coca-Cola) for adhesively bonded lithium disilicate crowns?

- Research Hypothesis: When comparing the microleakage depth and area, it is expected the treatment group subjected to the staining fluid of 'Coca-Cola' will have a statistically significant increase in microleakage depth and area when 
compared to the other treatment groups, including coffee, tea, and red wine, regardless of the type of direct restorative material used (Tetric EvoCeram, Tetric EvoCeram Bulk Fill, Tetric EvoFlow and Fuji II LC). The null hypothesis for the third research specific aim is that there will be no difference in microleakage depth or area in comparing staining fluids among treatment groups.

- Overall Research Hypothesis: The degree of microleakage of four staining fluids (coffee, tea, Coca-Cola, and red wine) will be larger for Tetric EvoFlow (nanohybrid flowable resin composite) than Tetric EvoCeram (nano-hybrid resin composite), Tetric EvoCeram Bulk Fill (nano-hybrid bulk fill resin composite), or Fuji II LC (resin-modified glass ionomer) amongst thermocycled and loaded class $\mathrm{V}$ restorations in teeth with a resin composite/ceramic crown restorative margin, with Coca-Cola exhibiting the largest area and depth of microleakage overall. 


\section{MATERIALS AND METHODS}

80 newly extracted, caries and restoration free maxillary and mandibular molars were collected from the oral surgery clinic at the University of Louisville School of Dentistry and local Oral Surgery offices in New Albany, Indiana. These specimens were cleaned and stored in 1:10 parts bleach to water solution to maintain the integrity of the teeth and prevent bacterial growth. The molars were randomly sorted into four different groups so that similar sized molars were in each group until n=20. Each group determined the type of beverage solution applied to the molar: Barefoot Cabernet Sauvignon Red Wine, original Coca-Cola, Lipton 100\% Natural Tea, and Folgers Classic Roast (Medium Brew), all adjusted to $\mathrm{pH} 4$.

Within each group of $n=20$, the samples received Class $V$ direct restorations with different types of composite. The class V dimensions were uniform across all 80 samples: approximately $4.0 \mathrm{~mm}$ (Incisal-Gingival) X 5-6 mm (Mesial-Distal) X 1.5-2 mm (axially) prepared with a 330-carbide bur (Brasseler Corp., Savannah, Georgia) and water coolant. The preparations were $2.0 \mathrm{~mm}(50 \%)$ above the CEJ and $2.0 \mathrm{~mm}(50 \%)$ below the CEJ. All preparations received incisal and gingival retention grooves with a $1 / 4$ round bur (Brasseler Corp., Savannah, Georgia).

The nano-hybrid resin composite preparations were conditioned with Total Etch (Ivoclar Vivadent, Liechtenstein) 37\% phosphoric acid etch for 15 seconds and rinsed for 15 seconds according to the manufacturer's recommendations. The resin-modified glass 
ionomer direct restorations were conditioned with $20 \%$ polyacrylic acid (GC Cavity Conditioner, GC America Corp, Tokyo, Japan) for 15 seconds and rinsed for 15 seconds, according to the manufacturer's recommendations. The nano-hybrid resin composite samples were lightly dried with an air-water syringe and treated with fifth-generation (single-bottle) bonding agent (ExciTE F VivaPen, Ivoclar Vivadent, Liechtenstein) according to the manufacturer's recommendations. These samples were then light-cured with a VLC light-cured with a calibrated (light intensity of 1,200 $\mathrm{mW} / \mathrm{cm}^{2}$ ) LED curing unit (BluePhase and BluePhase Meter, Ivoclar Vivadent, Liechtenstein) for 20 seconds.

The composite restorative materials applied to the samples differed. There were four different direct composites applied to the groups, with five samples per stain: nanohybrid resin composite (Tetric EvoCeram, Ivoclar Vivadent Corp), nano-hybrid bulk fill resin composite (Tetric EvoCeram Bulk Fill, Ivoclar Vivadent Corp), nano-hybrid flowable resin composite (Tetric EvoFlow, Ivoclar Vivadent Corp), and resin-modified glass ionomer (Fuji II LC, GC America). The composite restorations in each group were placed according to manufacturer recommendations, as placement technique can affect the restoration longevity. The nano-hybrid resin composite restorations were completed with a cross-hatch technique. The Fuji II LC resin-modified glass ionomer preparations were placed in bulk fill increments, according to the manufacturer's recommendations. These samples were then light-cured with a VLC light-cured with a calibrated (light intensity of 1,200 $\mathrm{mW} / \mathrm{cm}^{2}$ ) LED curing unit (BluePhase and BluePhase Meter, Ivoclar Vivadent, Liechtenstein) for 20 seconds. All specimen were polished with a 7901 Finishing Carbide Bur (Brasseler Corp., Savannah, Georgia) and water coolant. The restorations were: Teeth 1-20 were restored with Tetric EvoCeram nano-hybrid resin 
composite. Teeth 21-40 were restored with Tetric EvoCeram Bulk Fill nano-hybrid resin composite. Teeth 41-60 were restored with Tetric EvoFlow nano-hybrid resin composite. Teeth 61-80 were restored with GC Fuji II LC resin-modified glass ionomer.

Once the direct restorations were delivered and the samples were labeled, the 80 specimens were prepared for the pressed lithium disilicate full coverage ceramic crowns. The large chamfer margins had dimensions as follows: finish on the CEJ with axial reduction of $2 \mathrm{~mm}, 5-6 \mathrm{~mm}$ mesial-distal finished margin on direct restorative material as the treatment side, with $2 \mathrm{~mm}$ of direct restorative material incisal to the margin and 2 $\mathrm{mm}$ of direct restorative material gingival to the margin. The occlusal reduction was 2-3 $\mathrm{mm}$ to allow for ceramic thickness. The taper for the crown preparations was completed with the large chamfer bur, which allows 6-degrees of taper per preparation side, for a total of 12-degrees of taper converging occlusally. Once the preparations were completed and the teeth were mounted in mounting stone, the samples were taken to Roy Dental Labs in New Albany, IN, where digital impressions were taken of the samples. The teeth were dusted with Helling 3-D Laser Scanning Anti-Glare-Spray to improve digital scanning resolution before cycling through a Weiland 3-D scanner. Weiland digital software was used to create and contour lithium disilicate full ceramic crowns (IPS E.max, Ivoclar Vivadent, Liechtenstein). These were returned to the researcher. (During the process of crown formation, all 80 specimens were stored in 1:10 bleach solution). The crowns were then evaluated for marginal integrity. A self-etching dual-cured resin adhesive luting system (Multilink Automix, Ivoclar Vivadent, Liechtenstein) was used to cement the ceramic crowns. Multilink Primer A and B were mixed, scrubbed into crown preparations for 20 seconds, and air dried. A thin layer of self-etch resin luting agent 
was placed in the intaglio of the crown and the crowns were delivered via hand pressure. Excess luting agent was removed via hand instruments and $2 \times 2$ gauze. The margins were light-cured with the calibrated LED curing unit used in the direct restorations (BluePhase and BluePhase Meter, Ivoclar Vivadent, Liechtenstein). The specimen with the cemented crowns were polished, and labeled with the following direct restorations and staining fluids:

Teeth 1-5 were restored with Tetric EvoCeram nano-hybrid resin composite and subjected to original Coca-Cola staining. Teeth 6-10 were restored with Tetric EvoCeram nano-hybrid resin composite and subjected to Lipton 100\% natural tea staining. Teeth 1115 were restored with Tetric EvoCeram nano-hybrid resin composite and subjected to Barefoot Cabernet Sauvignon red wine staining. Teeth 16-20 were restored with Tetric EvoCeram nano-hybrid resin composite and subjected to Folgers classic roast (medium brew) staining. Teeth 21-25 were restored with Tetric EvoCeram Bulk Fill nano-hybrid resin composite and subjected to original Coca-Cola staining. Teeth 26-30 were restored with Tetric EvoCeram Bulk Fill nano-hybrid resin composite and subjected to Lipton 100\% natural tea staining. Teeth 31-35 were restored with Tetric EvoCeram Bulk Fill nano-hybrid resin composite and subjected to Barefoot Cabernet Sauvignon red wine staining. Teeth 36-40 were restored with Tetric EvoCeram Bulk Fill nano-hybrid resin composite and subjected to Folgers classic roast (medium brew) staining. Teeth 41-45 were restored with Tetric EvoFlow nano-hybrid resin composite and subjected to original Coca-Cola staining. Teeth 46-50 were restored with Tetric EvoFlow nano-hybrid resin composite and subjected to Lipton 100\% natural tea staining. Teeth 51-55 were restored with Tetric EvoFlow nano-hybrid resin composite and subjected to Barefoot Cabernet 
Sauvignon red wine staining. Teeth 56-60 were restored with Tetric EvoFlow nanohybrid resin composite and subjected to Folgers classic roast (medium brew) staining. Teeth 61-65 were restored with GC Fuji II LC resin-modified glass ionomer and subjected to original Coca-Cola staining. Teeth 66-70 were restored with GC Fuji II LC resin-modified glass ionomer and subjected to Lipton $100 \%$ natural tea staining. Teeth 71-75 were restored with GC Fuji II LC resin-modified glass ionomer and subjected to Barefoot Cabernet Sauvignon red wine staining. Teeth 75-80 were restored with GC Fuji II LC resin-modified glass ionomer and subjected to Folgers classic roast (medium brew) staining.

The dual restoration specimen were loaded into a cyclic uniaxial loader to simulate chewing force subjected on the teeth; this Instron testing machine put the teeth through $12 \mathrm{~Hz}$ for 10,000 cycles and variable compression (40-400 N) applied in the central fossa at an angle $15^{\circ}$ (buccal-lingual) to the long axis. A thermocycler was used after this step to simulate oral temperature cycles experienced in the mouth. Samples were surrounded by staining fluids specific to their groups (see above) and thermocycled from $6-60^{\circ} \mathrm{C}(5-$ minute dwell time) for 48 hours.

A diamond saw with copious water irrigation was used to section each specimen through the middle of the restorative material in three $2 \mathrm{~mm}$ sections. The treatment side of the tooth was the interface between the direct restoration and the indirect restoration, and the control side of the tooth was the interface between the indirect restoration and the dentin/enamel. After sectioning, each section was evaluated for depth and area of staining fluid penetration $(\mu \mathrm{m})$ under stereomicroscopy $(50 \mathrm{X})$ on both the treatment side and the control side using a 1 micron boxed dimensional grid. The three sagittal sectioned 
specimens were measured and averaged for an overall average staining fluid penetration value.

The penetration depth and area were measured for each control and treatment site and reported as mean beverage depth and area $(\mu \mathrm{m})+/$ - SD. Depth of staining fluid was measured from the cavosurface margin axially to the end of staining penetration in micrometers. Area of staining penetration was measured from the cavosurface margin axially as depth $\mathrm{X}$ width in micrometers. Significance was calculated using the t-table and a confidence interval of $95 \%$, or a p of 0.05 . Possible outliers were verified and reported. These average values were then analyzed to see if any of the staining fluids or resin composite materials have a microleakage depth that is greater than other samples and their confidence intervals. Significant differences between the microleakage amounts between different staining fluids and composites are enumerated in the results section.

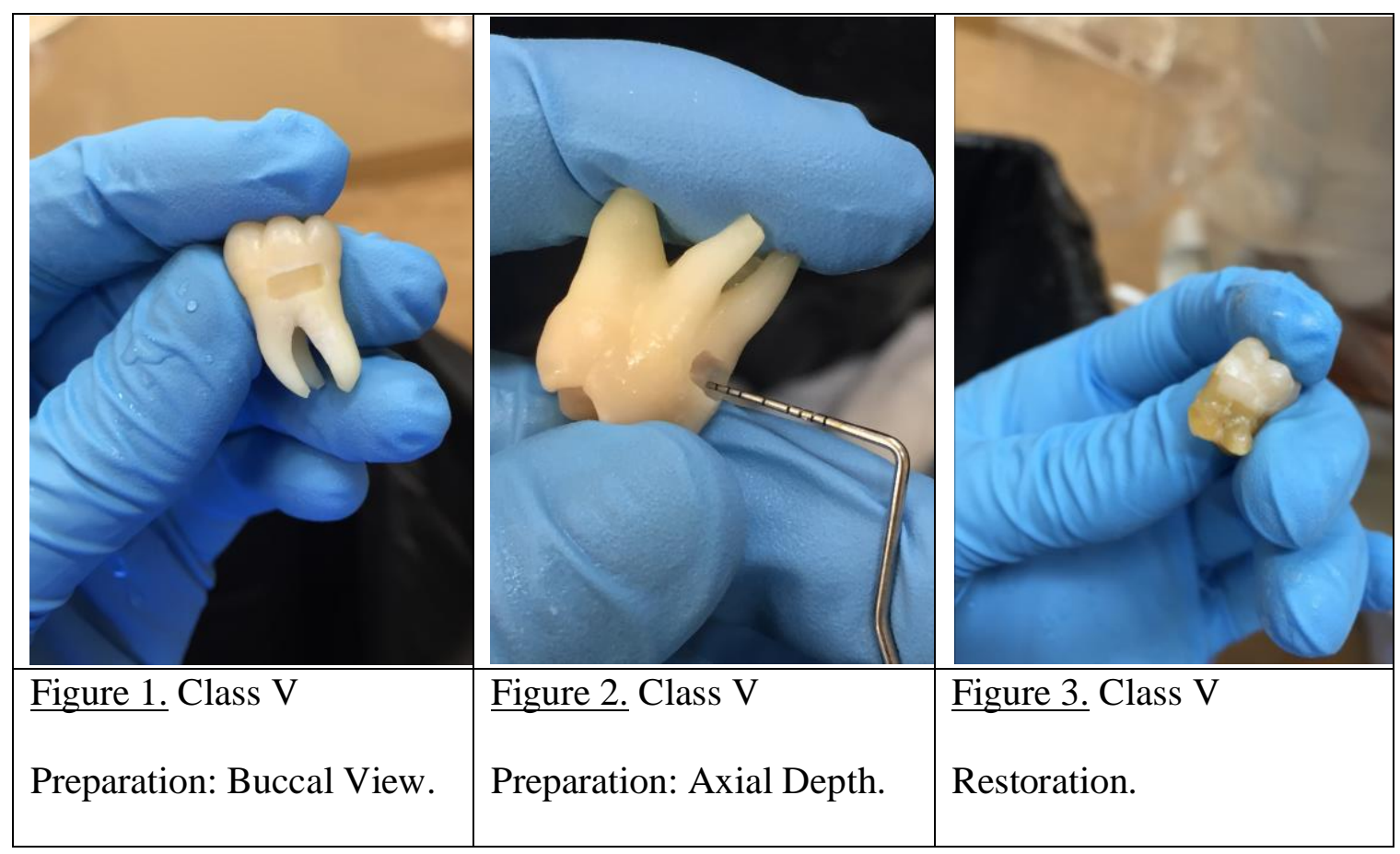




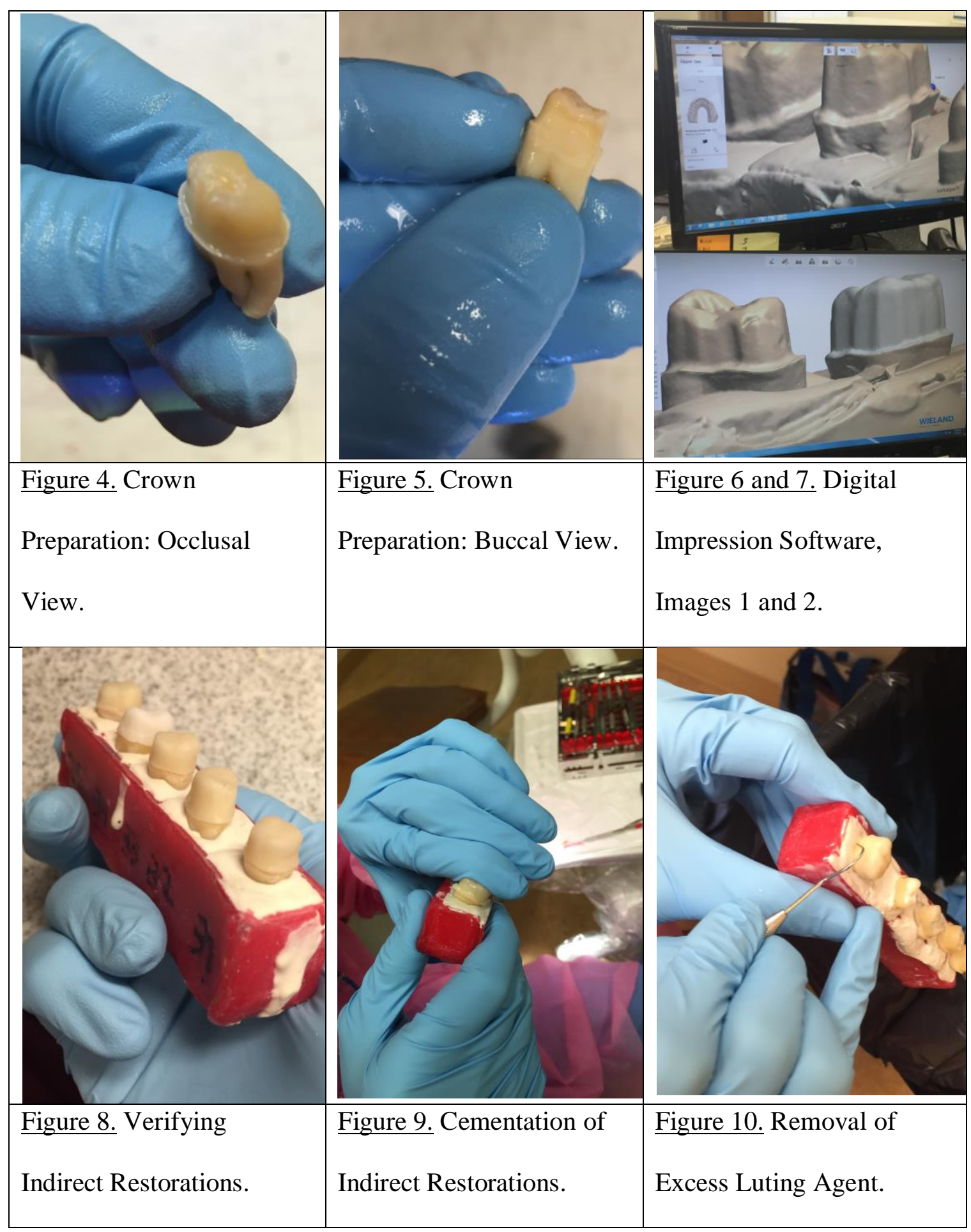



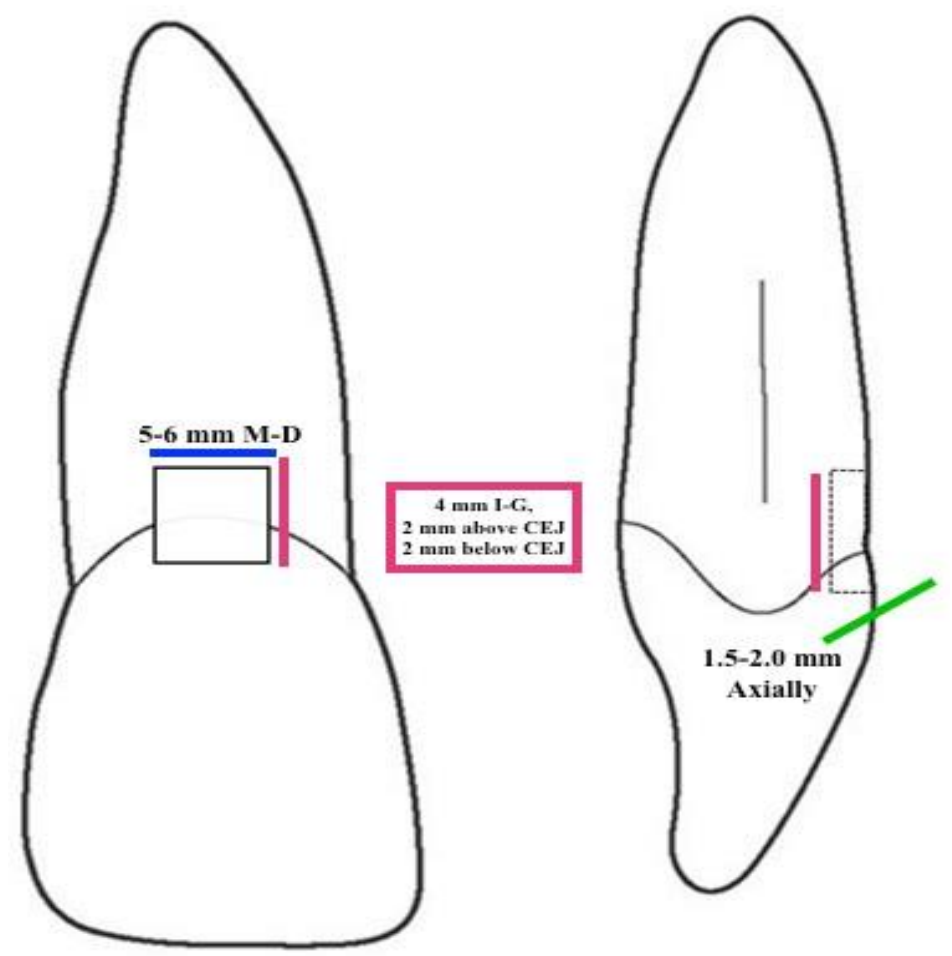

Figure 11. Class V Restoration placement and Dimensions.

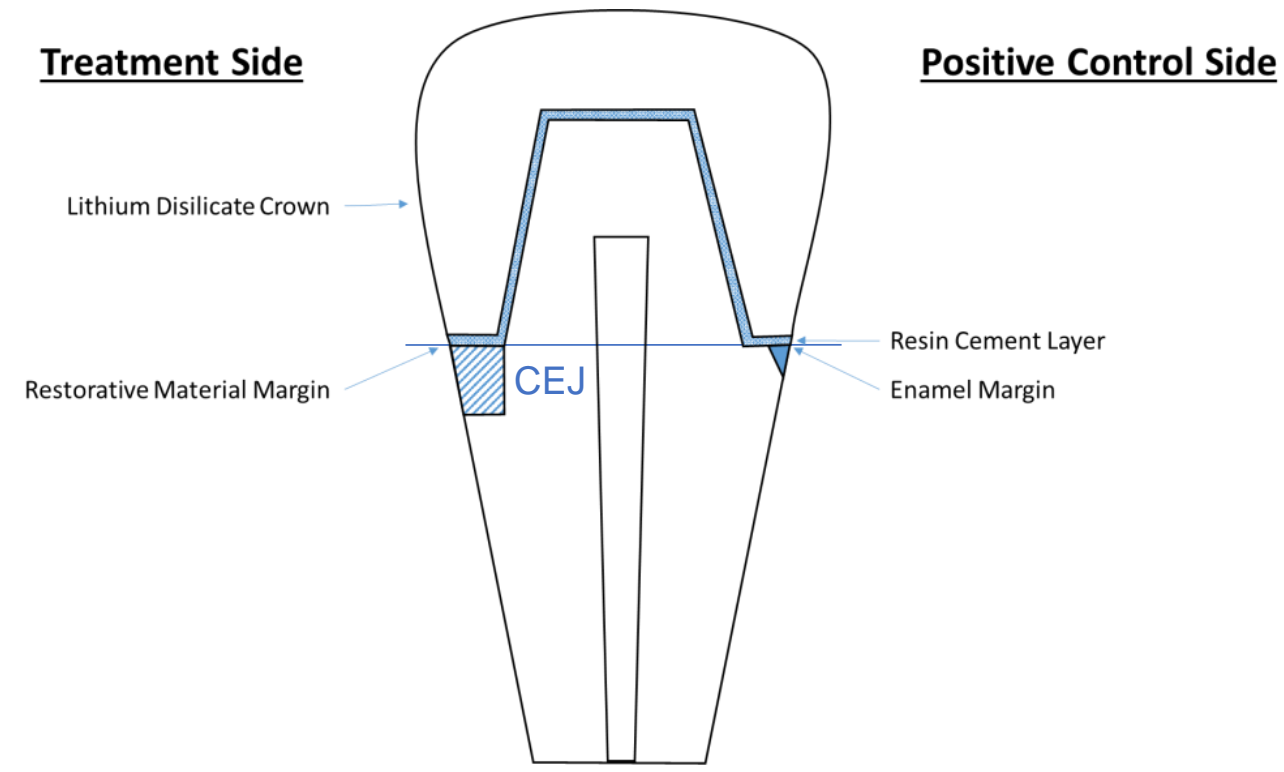

Figure 12. Treatment and Control Sides and Margin Finish Line Placement for Lithium Disilicate Indirect Restorations. 


\section{RESULTS}

\section{Table 1}

\section{Variables in Study}

\begin{tabular}{|c|c|c|c|c|}
\hline \multicolumn{4}{|c|}{ Independent Variables/Input } & Dependent Variables/Output \\
\hline \multicolumn{4}{|c|}{ Liquid Media/Staining Fluid (all adjusted to $\mathrm{pH} 4$ ) } & Area of Stain Penetration $(\mu \mathrm{m})$ \\
\hline Cola & $\begin{array}{l}\text { Lipton } 100 \% \\
\text { Natural Tea }\end{array}$ & $\begin{array}{l}\text { Barefoot } \\
\text { Cabernet } \\
\text { Sauvignon }\end{array}$ & $\begin{array}{l}\text { Folgers Classic } \\
\text { Roast (Medium } \\
\text { Brew) }\end{array}$ & $\begin{array}{l}\text { Area of staining penetration was } \\
\text { measured from the cavosurface } \\
\text { margin axially as depth } \mathrm{X} \text { width in } \\
\text { micrometers }\end{array}$ \\
\hline $\mathrm{N}=20$ & $\mathrm{~N}=20$ & $\mathrm{~N}=20$ & $\mathrm{~N}=20$ & $\begin{array}{c}\mathrm{N}=5 \text { for treatment groups } \\
\mathrm{N}=20 \text { for control groups (on the } \\
\text { opposite side of the tooth) }\end{array}$ \\
\hline \multicolumn{4}{|c|}{ Restorative Material Type (Same Class V Restoration Dimensions and Placement) } & Depth of Stain Penetration $(\mu \mathrm{m})$ \\
\hline Tetric EvoCeram & Tetric EvoCeram & Tetric EvoFlow & Fuji II LC Resin- & Depth of Stain Penetration was \\
\hline Nano-Hybrid & Bulk Fill Nano- & Nano-Hybrid & Modified Glass & measured from the cavosurface \\
\hline Resin Composite & $\begin{array}{l}\text { Hybrid Resin } \\
\text { Composite }\end{array}$ & Resin Composite & Ionomer & $\begin{array}{l}\text { margin axially to the end of staining } \\
\text { penetration in micrometers. }\end{array}$ \\
\hline $\mathrm{N}=20$ & $\mathrm{~N}=20$ & $\mathrm{~N}=20$ & $\mathrm{~N}=20$ & $\begin{array}{l}\mathrm{N}=5 \text { for treatment groups } \\
\mathrm{N}=20 \text { for control groups (on the } \\
\text { opposite side of the tooth) }\end{array}$ \\
\hline $\begin{array}{r}37 \% \text { Phosp } \\
\text { Adhesive Restora }\end{array}$ & $\begin{array}{l}\text { ric Acid Condition } \\
\text { n Bonding - ExciT } \\
\text { N=60 }\end{array}$ & $\begin{array}{l}\text { Total Etch }) \\
\left(5^{\text {th }} \text { Generation }\right)\end{array}$ & $\begin{array}{l}\text { 20\% Polyacrylic } \\
\text { Acid Conditioner } \\
\qquad \mathrm{N}=20\end{array}$ & \\
\hline \multicolumn{4}{|c|}{$\begin{array}{l}\text { IPS E. Max All-Ceramic Crown Pressed Luting - } \\
\text { Multilink Automix Resin Adhesive Luting System }\end{array}$} & \\
\hline
\end{tabular}




\section{Table 2}

Mean Depth and Area +/- SD $(\mu \mathrm{m})$.

\begin{tabular}{|c|c|c|c|c|c|c|c|}
\hline $\begin{array}{l}\text { Sample } \\
\text { Number }\end{array}$ & $\begin{array}{l}\text { Sample } \\
\text { Size }\end{array}$ & $\begin{array}{l}\text { Staining } \\
\text { Fluid }\end{array}$ & $\begin{array}{l}\text { Direct } \\
\text { Restoration }\end{array}$ & $\begin{array}{l}\text { Stain Area } \\
\text { Penetration } \\
(\mu \mathrm{m})\end{array}$ & $\begin{array}{l}\text { Area SD } \\
(\mu \mathrm{m})\end{array}$ & $\begin{array}{l}\text { Stain Depth } \\
\text { Penetration } \\
(\mu \mathrm{m})\end{array}$ & $\begin{array}{l}\text { Depth SD } \\
(\mu \mathrm{m})\end{array}$ \\
\hline $1-5$ & $\begin{array}{l}\mathrm{N}=5 \times 3 \\
\text { sections }\end{array}$ & Cola & $\begin{array}{l}\text { EvoCeram Nano- } \\
\text { Hybrid RC }\end{array}$ & 11270.2000 & 617.94312 & 255.8000 & 10.05982 \\
\hline $6-10$ & $\begin{array}{l}\mathrm{N}=5 \times 3 \\
\text { sections }\end{array}$ & Tea & $\begin{array}{l}\text { EvoCeram Nano- } \\
\text { Hybrid RC }\end{array}$ & 11392.2000 & 677.63316 & 258.0000 & 13.67479 \\
\hline $11-15$ & $\begin{array}{l}\mathrm{N}=5 \times 3 \\
\text { sections }\end{array}$ & Wine & $\begin{array}{l}\text { EvoCeram Nano- } \\
\text { Hybrid RC }\end{array}$ & 11392.2000 & 677.63316 & 253.4000 & 7.92465 \\
\hline $16-20$ & $\begin{array}{l}\mathrm{N}=5 \times 3 \\
\text { sections }\end{array}$ & Coffee & $\begin{array}{l}\text { EvoCeram Nano- } \\
\text { Hybrid RC }\end{array}$ & 11367.4000 & 651.59673 & 258.0000 & 13.67479 \\
\hline $21-25$ & $\begin{array}{l}\mathrm{N}=5 \times 3 \\
\text { sections }\end{array}$ & Cola & $\begin{array}{l}\text { EvoCeram Bulk } \\
\text { Fill Nano-Hybrid } \\
\text { RC }\end{array}$ & 11392.2000 & 677.63316 & 258.0000 & 13.67479 \\
\hline $26-30$ & $\begin{array}{l}\mathrm{N}=5 \times 3 \\
\text { sections }\end{array}$ & Tea & $\begin{array}{l}\text { EvoCeram Bulk } \\
\text { Fill Nano-Hybrid } \\
\text { RC }\end{array}$ & 11392.2000 & 677.63316 & 253.4000 & 7.92465 \\
\hline $31-35$ & $\begin{array}{l}\mathrm{N}=5 \times 3 \\
\text { sections }\end{array}$ & Wine & $\begin{array}{l}\text { EvoCeram Bulk } \\
\text { Fill Nano-Hybrid } \\
\text { RC }\end{array}$ & 11367.4000 & 651.59673 & 258.0000 & 13.67479 \\
\hline $36-40$ & $\begin{array}{l}\mathrm{N}=5 \times 3 \\
\text { sections }\end{array}$ & Coffee & $\begin{array}{l}\text { EvoCeram Bulk } \\
\text { Fill Nano-Hybrid } \\
\text { RC }\end{array}$ & 11392.2000 & 677.63316 & 258.0000 & 13.67479 \\
\hline $41-45$ & $\begin{array}{l}\mathrm{N}=5 \times 3 \\
\text { sections }\end{array}$ & Cola & $\begin{array}{l}\text { EvoFlow Nano- } \\
\text { Hybrid RC }\end{array}$ & 32234.4000 & 1023.05880 & 415.2000 & 14.92314 \\
\hline $46-50$ & $\begin{array}{l}\mathrm{N}=5 \times 3 \\
\text { sections }\end{array}$ & Tea & $\begin{array}{l}\text { EvoFlow Nano- } \\
\text { Hybrid RC }\end{array}$ & 32434.4000 & 789.27137 & 394.6000 & 61.95402 \\
\hline $51-55$ & $\begin{array}{l}\mathrm{N}=5 \times 3 \\
\text { sections }\end{array}$ & Wine & $\begin{array}{l}\text { EvoFlow Nano- } \\
\text { Hybrid RC }\end{array}$ & 32034.4000 & 1367.60714 & 396.6000 & 63.32693 \\
\hline $56-60$ & $\begin{array}{l}\mathrm{N}=5 \times 3 \\
\text { sections }\end{array}$ & Coffee & $\begin{array}{l}\text { EvoFlow Nano- } \\
\text { Hybrid RC }\end{array}$ & 31859.2000 & 1708.97212 & 405.2000 & 72.15054 \\
\hline
\end{tabular}




\begin{tabular}{|c|c|c|c|c|c|c|c|}
\hline $61-65$ & $\begin{array}{l}\mathrm{N}=5 \times 3 \\
\text { sections }\end{array}$ & Cola & $\begin{array}{l}\text { GC Fuji II LC } \\
\text { Resin-modified } \\
\text { GI }\end{array}$ & 11392.2000 & 677.63316 & 258.0000 & 13.67479 \\
\hline $66-70$ & $\begin{array}{l}\mathrm{N}=5 \times 3 \\
\text { sections }\end{array}$ & Tea & $\begin{array}{l}\text { GC Fuji II LC } \\
\text { Resin-modified } \\
\text { GI }\end{array}$ & 11392.2000 & 677.63316 & 253.4000 & 7.92465 \\
\hline $71-75$ & $\begin{array}{l}\mathrm{N}=5 \times 3 \\
\text { sections }\end{array}$ & Wine & $\begin{array}{l}\text { GC Fuji II LC } \\
\text { Resin-modified } \\
\text { GI }\end{array}$ & 11367.4000 & 651.59673 & 258.0000 & 13.67479 \\
\hline $76-80$ & $\begin{array}{l}\mathrm{N}=5 \times 3 \\
\text { sections }\end{array}$ & Coffee & $\begin{array}{l}\text { GC Fuji II LC } \\
\text { Resin-modified } \\
\text { GI }\end{array}$ & 11392.2000 & 677.63316 & 258.0000 & 13.67479 \\
\hline $\begin{array}{l}1-5, \\
21-25, \\
41-45, \\
61-65\end{array}$ & $\begin{array}{l}\mathrm{N}=20 \times 3 \\
\text { sections }\end{array}$ & Cola & Control & 11695.6500 & 800.92100 & 259.6000 & 11.63660 \\
\hline $\begin{array}{l}6-10, \\
26-30, \\
46-50, \\
66-70\end{array}$ & $\begin{array}{l}\mathrm{N}=20 \times 3 \\
\text { sections }\end{array}$ & Tea & Control & 11895.8500 & 904.72039 & 256.5500 & 11.92730 \\
\hline $\begin{array}{l}11-15, \\
31-35, \\
51-55, \\
71-75\end{array}$ & $\begin{array}{l}\mathrm{N}=20 \times 3 \\
\text { sections }\end{array}$ & Wine & Control & 11735.3500 & 949.20500 & 257.1500 & 11.97047 \\
\hline $\begin{array}{l}16-20, \\
36-40, \\
56-60, \\
76-80\end{array}$ & $\begin{array}{l}\mathrm{N}=20 \times 3 \\
\text { sections }\end{array}$ & Coffee & Control & 11706.3500 & 991.95179 & 254.7500 & 12.72741 \\
\hline
\end{tabular}




\section{Table 3}

Overall Mean Depth and Area: Significance

\begin{tabular}{|l|l|l|l|}
\hline Variable & Test & Significance & Meaning \\
\hline Liquid Depth & Wilks' Lambda & 0.745 & Not Significant, >0.05 \\
\hline Liquid Area & Wilks' Lambda & 0.916 & Not Significant, >0.05 \\
\hline Restorative Material Depth & Wilks' Lambda & 0.000 & Significant, <0.05 \\
\hline Restorative Material Area & Wilks' Lambda & 0.000 & Significant, <0.05 \\
\hline
\end{tabular}

Table 4

Pairwise Comparisons for Liquids

\begin{tabular}{|c|c|c|c|c|}
\hline Dependent Variable & Liquid Media Group & $\begin{array}{l}\text { Liquid Media } \\
\text { Group }\end{array}$ & Std. Error & Sig* \\
\hline \multirow[t]{12}{*}{ Microleakage Depth } & \multirow[t]{3}{*}{ Coca-Cola } & Tea & 5.886 & .299 \\
\hline & & Wine & 5.886 & .427 \\
\hline & & Coffee & 5.886 & .668 \\
\hline & \multirow[t]{3}{*}{ Tea } & Coca-Cola & 5.886 & .299 \\
\hline & & Wine & 5.886 & 807 \\
\hline & & Coffee & 5.886 & .542 \\
\hline & \multirow[t]{3}{*}{ Wine } & Coca-Cola & 5.886 & .427 \\
\hline & & Tea & 5.886 & 807 \\
\hline & & Coffee & 5.886 & .714 \\
\hline & \multirow[t]{3}{*}{ Coffee } & Coca-Cola & 5.886 & .668 \\
\hline & & Tea & 5.886 & .542 \\
\hline & & Wine & 5.886 & .714 \\
\hline
\end{tabular}




\begin{tabular}{|c|c|c|c|c|}
\hline Microleakage Area & Coca-Cola & Tea & 231.894 & .653 \\
\hline (microns) & & Wine & 231.894 & .940 \\
\hline & & Coffee & 231.894 & .818 \\
\hline & Tea & Coca-Cola & 231.894 & .653 \\
\hline & & Wine & 231.894 & .600 \\
\hline & & Coffee & 231.894 & .497 \\
\hline & Wine & Coca-Cola & 231.894 & .940 \\
\hline & & Tea & 231.894 & .600 \\
\hline & & Coffee & 231.894 & .877 \\
\hline & Coffee & Coca-Cola & 231.894 & .818 \\
\hline & & Tea & 231.894 & .497 \\
\hline & & Wine & 231.894 & .877 \\
\hline
\end{tabular}

Table 5

Pairwise Comparisons for Restorative Groups

\begin{tabular}{|c|c|c|c|c|c|c|c|}
\hline \multirow{2}{*}{$\begin{array}{l}\text { Dependent } \\
\text { Variable }\end{array}$} & \multirow{2}{*}{$\begin{array}{l}\text { (I) Restorative } \\
\text { Material Groups }\end{array}$} & \multirow{2}{*}{$\begin{array}{l}\text { (J) Restorative } \\
\text { Material Groups }\end{array}$} & \multirow{2}{*}{$\begin{array}{l}\text { Mean } \\
\text { Difference } \\
\text { (I-J) }\end{array}$} & \multirow{2}{*}{$\begin{array}{l}\text { Std. } \\
\text { Error }\end{array}$} & \multirow[b]{2}{*}{ Sig." } & \multicolumn{2}{|c|}{$\begin{array}{l}95 \% \text { Confidence Interval for } \\
\text { Difference }\end{array}$} \\
\hline & & & & & & Lower Bound & Upper Bound \\
\hline \multirow[t]{3}{*}{$\begin{array}{l}\text { Microleakage } \\
\text { Depth (microns) }\end{array}$} & \multirow[t]{3}{*}{$\begin{array}{l}\text { Tetric } \\
\text { EvoCeram NH } \\
\text { RC }\end{array}$} & $\begin{array}{l}\text { EvoCeram } \\
\text { Bulk Fill NH } \\
\text { RC }\end{array}$ & -.550 & 7.138 & .939 & -14.662 & 13.562 \\
\hline & & $\begin{array}{l}\text { EvoFlow NH } \\
\text { RC }\end{array}$ & $-146.600^{*}$ & 7.138 & .000 & -160.712 & -132.488 \\
\hline & & $\begin{array}{l}\text { Glass Ionomer } \\
\text { RM }\end{array}$ & -.550 & 7.138 & .939 & -14.662 & 13.562 \\
\hline
\end{tabular}




\begin{tabular}{|c|c|c|c|c|c|c|}
\hline & Control & -.713 & 5.643 & .900 & -11.869 & 10.444 \\
\hline $\begin{array}{l}\text { Tetric } \\
\text { EvoCeram Bulk }\end{array}$ & $\begin{array}{l}\text { EvoCeram NH } \\
\text { RC }\end{array}$ & .550 & 7.138 & .939 & -13.562 & 14.662 \\
\hline \multirow[t]{3}{*}{ Fill NH RC } & $\begin{array}{l}\text { EvoFlow NH } \\
\text { RC }\end{array}$ & $-146.050^{*}$ & 7.138 & .000 & -160.162 & -131.938 \\
\hline & $\begin{array}{l}\text { Glass Ionomer } \\
\text { RM }\end{array}$ & $3.220 \mathrm{E}-15$ & 7.138 & 1.00 & -14.112 & 14.112 \\
\hline & Control & -.163 & 5.643 & .977 & -11.319 & 10.994 \\
\hline \multirow[t]{4}{*}{$\begin{array}{l}\text { Tetric EvoFlow } \\
\text { NH RC }\end{array}$} & $\begin{array}{l}\text { EvoCeram NH } \\
\text { RC }\end{array}$ & $146.600^{*}$ & 7.138 & .000 & 132.488 & 160.712 \\
\hline & $\begin{array}{l}\text { EvoCeram } \\
\text { Bulk Fill NH } \\
\text { RC }\end{array}$ & $146.050^{*}$ & 7.138 & .000 & 131.938 & 160.162 \\
\hline & $\begin{array}{l}\text { Glass Ionomer } \\
\text { RM }\end{array}$ & $146.050^{*}$ & 7.138 & .000 & 131.938 & 160.162 \\
\hline & Control & $145.888^{*}$ & 5.643 & .000 & 134.731 & 157.044 \\
\hline \multirow[t]{4}{*}{$\begin{array}{l}\text { Glass Ionomer } \\
\text { RM }\end{array}$} & $\begin{array}{l}\text { EvoCeram NH } \\
\text { RC }\end{array}$ & I. .550 & 7.138 & .939 & -13.562 & 14.662 \\
\hline & $\begin{array}{l}\text { EvoCeram } \\
\text { Bulk Fill NH } \\
\text { RC }\end{array}$ & $-3.220 \mathrm{E}-15$ & 7.138 & 1.00 & -14.112 & 14.112 \\
\hline & $\begin{array}{l}\text { EvoFlow NH } \\
\text { RC }\end{array}$ & $-146.050^{*}$ & 7.138 & .000 & -160.162 & -131.938 \\
\hline & Control & -.163 & 5.643 & .977 & -11.319 & 10.994 \\
\hline Control & $\begin{array}{l}\text { EvoCeram NH } \\
\text { RC }\end{array}$ & .713 & 5.643 & .900 & -10.444 & 11.869 \\
\hline
\end{tabular}




\begin{tabular}{|c|c|c|c|c|c|c|c|}
\hline & & $\begin{array}{l}\text { EvoCeram } \\
\text { Bulk Fill NH } \\
\text { RC }\end{array}$ & .163 & 5.643 & .977 & -10.994 & 11.319 \\
\hline & & $\begin{array}{l}\text { EvoFlow NH } \\
\text { RC }\end{array}$ & $-145.888^{*}$ & 5.643 & .000 & -157.044 & -134.731 \\
\hline & & $\begin{array}{l}\text { Glass Ionomer } \\
\text { RM }\end{array}$ & .163 & 5.643 & .977 & -10.994 & 11.319 \\
\hline $\begin{array}{l}\text { Microleakage } \\
\text { Area (microns) }\end{array}$ & $\begin{array}{l}\text { Tetric } \\
\text { EvoCeram NH } \\
\text { RC }\end{array}$ & $\begin{array}{l}\text { EvoCeram } \\
\text { Bulk Fill NH } \\
\text { RC }\end{array}$ & -30.500 & 281.212 . & .914 & -586.472 & 525.472 \\
\hline & & $\begin{array}{l}\text { EvoFlow NH } \\
\text { RC }\end{array}$ & $-20785.10^{*}$ & 281.212 & .000 & -21341.072 & -20229.128 \\
\hline & & $\begin{array}{l}\text { Glass Ionomer } \\
\text { RM }\end{array}$ & -30.500 & 281.212 & .914 & -586.472 & 525.472 \\
\hline & & Control & -402.800 & 222.318 & .072 & -842.334 & 36.734 \\
\hline & $\begin{array}{l}\text { Tetric } \\
\text { EvoCeram Bulk }\end{array}$ & $\begin{array}{l}\text { EvoCeram NH } \\
\text { RC }\end{array}$ & 30.500 & 281.212 & .914 & -525.472 & 586.472 \\
\hline & Fill NH RC & $\begin{array}{l}\text { EvoFlow NH } \\
\text { RC }\end{array}$ & $-20754.60^{*}$ & 281.212 & .000 & -21310.572 & -20198.628 \\
\hline & & $\begin{array}{l}\text { Glass Ionomer } \\
\text { RM }\end{array}$ & $1.073 \mathrm{E}-12$ & 281.212 & 1.000 & -555.972 & 555.972 \\
\hline & & Control & -372.300 & 222.318 & .096 & -811.834 & 67.234 \\
\hline & $\begin{array}{l}\text { Tetric EvoFlow } \\
\text { NH RC }\end{array}$ & $\begin{array}{l}\text { EvoCeram NH } \\
\text { RC }\end{array}$ & $20785.100^{*}$ & 281.212 & .000 & 20229.128 & 21341.072 \\
\hline
\end{tabular}




\begin{tabular}{|c|c|c|c|c|c|c|}
\hline & $\begin{array}{l}\text { EvoCeram } \\
\text { Bulk Fill NH } \\
\text { RC }\end{array}$ & 20754.600* & 281.212 . & .000 & 20198.628 & 21310.572 \\
\hline & $\begin{array}{l}\text { Glass Ionomer } \\
\text { RM }\end{array}$ & $20754.600 *$ & 281.212 & .000 & 20198.628 & 21310.572 \\
\hline & Control & 20382.300* & 222.318 & .000 & 19942.766 & 20821.834 \\
\hline \multirow[t]{4}{*}{$\begin{array}{l}\text { Glass Ionomer } \\
\text { RM }\end{array}$} & $\begin{array}{l}\text { EvoCeram NH } \\
\text { RC }\end{array}$ & 30.500 & 281.212 . & .914 & -525.472 & 586.472 \\
\hline & $\begin{array}{l}\text { EvoCeram } \\
\text { Bulk Fill NH } \\
\text { RC }\end{array}$ & $-1.073 \mathrm{E}-12$ & 281.212 & 1.000 & $0-555.972$ & 555.972 \\
\hline & $\begin{array}{l}\text { EvoFlow NH } \\
\text { RC }\end{array}$ & $-20754.60^{*}$ & 281.212 & .000 & -21310.572 & -20198.628 \\
\hline & Control & -372.300 & 222.318 & .096 & -811.834 & 67.234 \\
\hline \multirow[t]{4}{*}{ Control } & $\begin{array}{l}\text { EvoCeram NH } \\
\text { RC }\end{array}$ & 402.800 & 222.318 & .072 & -36.734 & 842.334 \\
\hline & $\begin{array}{l}\text { EvoCeram } \\
\text { Bulk Fill NH } \\
\text { RC }\end{array}$ & 372.300 & 222.318 & .096 & -67.234 & 811.834 \\
\hline & $\begin{array}{l}\text { EvoFlow NH } \\
\text { RC }\end{array}$ & $-20382.30^{*}$ & 222.318 . & .000 & -20821.834 & -19942.766 \\
\hline & $\begin{array}{l}\text { Glass Ionomer } \\
\text { RM }\end{array}$ & 372.300 & 222.318 . & .096 & -67.234 & 811.834 \\
\hline
\end{tabular}




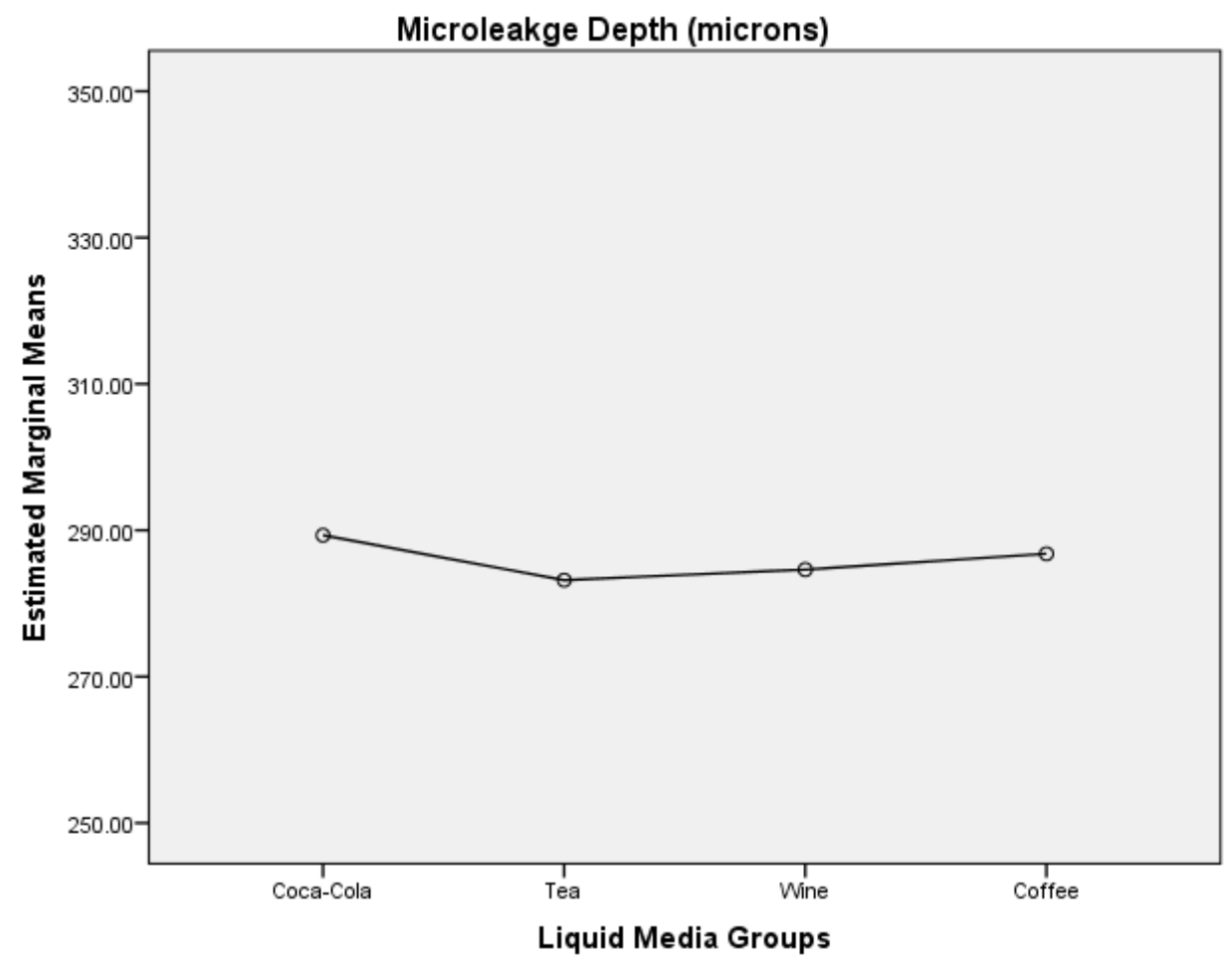

Figure 13. Microleakage Depth (microns) for Liquid Media Groups.

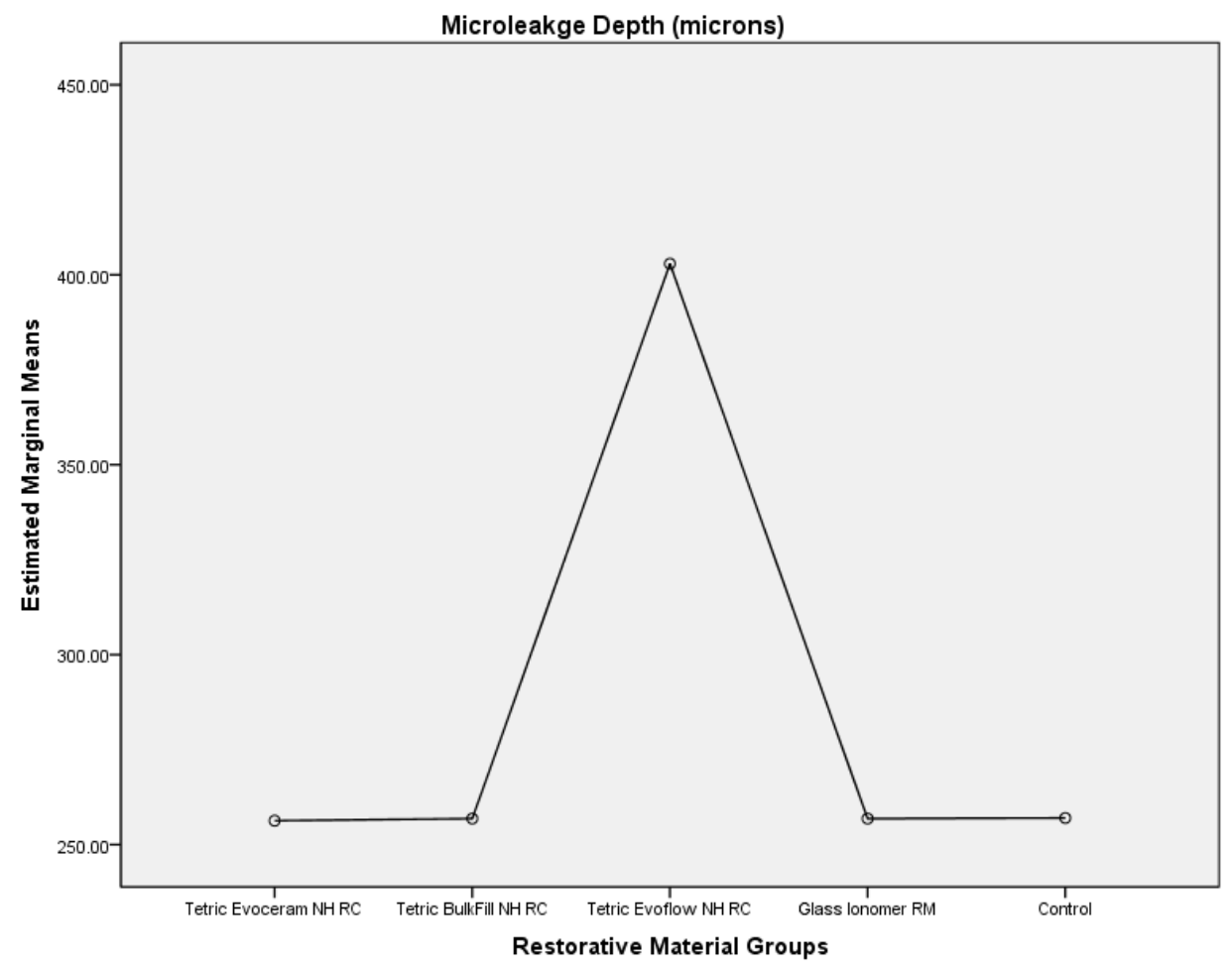

Figure 14. Microleakage Depth (microns) for Restorative Material Groups. 


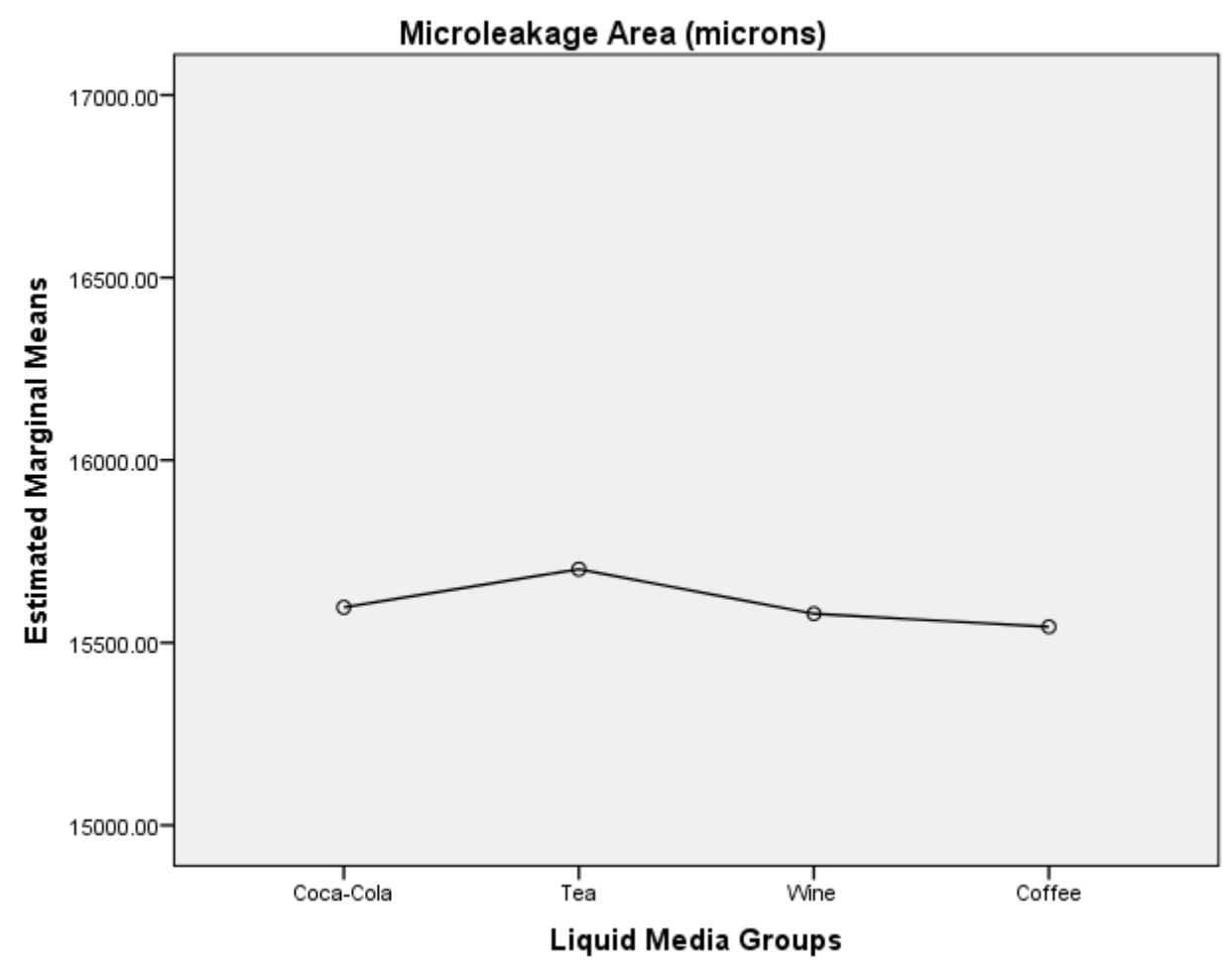

Figure 15. Microleakage Area (microns) for Liquid Media Groups.

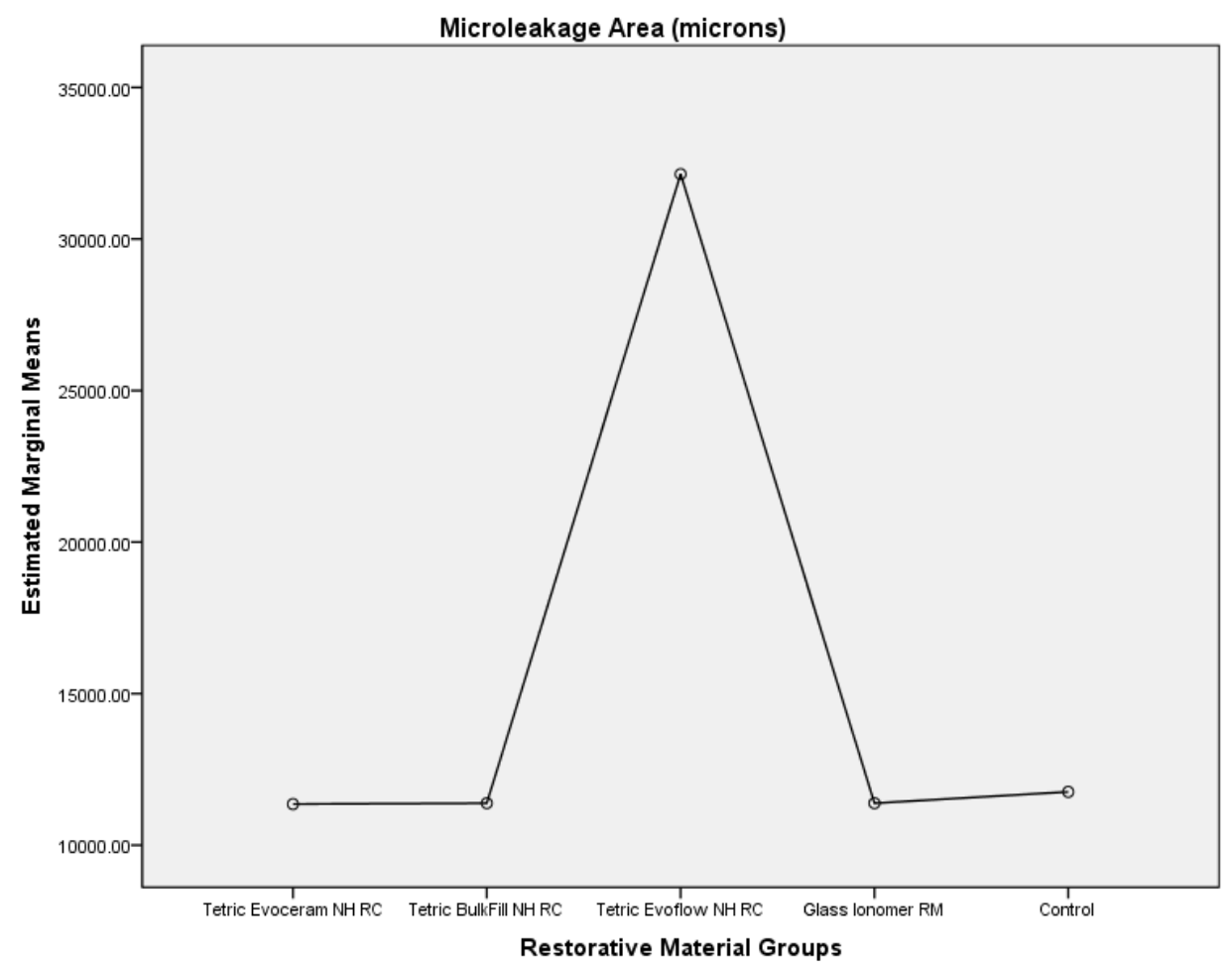

Figure 16. Microleakage Area (microns) for Restorative Material Groups. 


\section{DATA ANALYSIS}

Figures 1-10 can be seen at the beginning of the results section. These are images taken during preparation of the specimen for testing. Figures 1-2 depict the direct restoration preparation of all 80 specimen. As stated in the materials and methods section, the preparation was approximately $4.0 \mathrm{~mm}$ (Incisal-Gingival) X 5.0-6.0 $\mathrm{mm}$ (MesialDistal) X 1.5-2.0 mm (axially), was located $2.0 \mathrm{~mm}(50 \%)$ above the CEJ and $2.0 \mathrm{~mm}$ (50\%) below the CEJ, and contained incisal and gingival retention grooves. Figure 3 depicts the completed direct restoration in the 80 specimens, placed according to the manufacturer's recommendations (see materials and methods section for specific details). Figures 4 and 5 depict the indirect restoration completed for the 80 specimens, which was finished on the CEJ. Dimensions for the indirect restoration preparation, as stated in the materials and methods section, are: axial reduction of $2 \mathrm{~mm}, 2 \mathrm{~mm}$ incisal finished margin above the crown margin and $2 \mathrm{~mm}$ gingival finished margin below the crown margin, 2-3 mm of occlusal reduction, and 12-degrees of occlusal convergence/taper with a large chamfer diamond bur. Figures 6 and 7 depict the laboratory process of scanning and designing the crown copings prior to fabrication. Figure 8 depicts the completed and returned crowns ready for cementation for a group of treatment specimen. Each crown was inspected for marginal integrity prior to cementation. Figures 9 and 10 depict cementation and polishing/final specimen preparations. This was completed according to the materials and methods section (see above). At this point, the specimens were sent to 
the laboratory in Indianapolis, IN for Instron load testing, thermocycling, staining with one of the four common staining fluids, sectioning, and data collection (see materials and methods).

Figures 11 and 12 give pictorial representations of the direct and indirect restorations. Figure 11 gives the Class V incisal-gingival, mesial-distal, and axial dimensions of the different Class $\mathrm{V}$ restorative material restorations. Note: this is the treatment side of the tooth; the control side of the tooth is the opposite side of the tooth, without a direct restoration. Figure 12 gives this representation of the treatment and control sides of the tooth and represents the finish lines for the lithium disilicate crown.

Table 1 gives the independent and dependent variables for this research project. The independent variables were the staining media (original Coca-Cola, Lipton 100\% natural tea, Barefoot Cabernet Sauvignon red wine, and Folgers classic roast (medium brew) coffee) and the type of direct restorative material used (Tetric EvoCeram nano-hybrid resin composite, Tetric EvoCeram Bulk Fill nano-hybrid resin composite, Tetric EvoFlow nano-hybrid resin composite, and Fuji II LC resin-modified glass ionomer). All of these independent variables have an $n=20$, meaning that when they are combined (ex: Coca-Cola and Tetric EvoFlow nano-hybrid resin composite), each treatment group has a $\mathrm{n}=5$. Preparations applied to the specimen are listed under the restorative materials. The Tetric resin composites received total etch and ExciTE F $5^{\text {th }}$ generation bonding agent; the Fuji II LC resin-modified glass ionomer specimen received polyacrylic acid conditioner. All samples received the same indirect restoration treatment. The dependent variables were the depth and area of stain penetration in the resulting specimen after testing. Please note that the treatment groups' staining was measured at the interface of 
the direct and indirect restorative material and the control groups' staining was measured at the interface of the dental tissue and the indirect restorative material. As stated in the materials and methods section of the paper, the staining was measured using stereomicroscopy (50X) and a one-micron box measurement grid. Depth of staining fluid penetration was measured from the cavosurface margin axially to the end of staining penetration in micrometers. Area of staining penetration was measured from the cavosurface margin axially as depth $\mathrm{X}$ width in micrometers.

Table 2 gives the mean staining depth and area for each group. The number identifiers are listed in the first column, from 1-80. Please note that each tooth had a control and a treatment side. The control measurements differed in the staining media only (20 teeth per average), the treatment measurements differed in both restorative types and staining media ( 5 teeth per average). There were three $2 \mathrm{~mm}$ slices taken per tooth, thus the average depth and areas of penetration consists of three measurements/tooth $\mathrm{x} 5$ teeth for the treatment averages and three measurements/tooth $\times 20$ teeth for the control averages. According to the results, there was 0.000 Significance for Box's Test of Equality of Covariance Matrices, meaning the samples were consistent in testing; no outliers were removed from testing in order to achieve more accurate statistic results. The standard deviations are listed to the right of the depth and area values for each sample group. These values underwent ANOVA testing to determine descriptive statistics.

Penetration of staining fluids and restorative materials were analyzed via analysis of variance (ANOVA) testing, in which any values less than an accepted $p$ value (in this case $p<0.05)$ are deemed significant. In Table 3 , it can be seen that liquid media depth and area of penetration values are both $\mathrm{p}>0.05(0.745,0.916$, respectively), meaning that 
there is not a statistically significant different value in the measurements between the liquid media groups. For the restorative material groups, both the depth and the area are $\mathrm{p}<0.05$ with $\mathrm{p}$ values of 0.00 . This means that there is significance between restorative materials in terms of depth and area of staining penetration.

Table 4 depicts pairwise comparisons for the liquid testing groups. A Tukey's posthoc analysis was performed and determined that all treatment groups were statistically insignificant in terms of microleakage depth and area of penetration. All $p$ values were greater than $\mathrm{p}<0.05$. This confirms findings in Table 3 , that there was not a statistically significant difference between the liquid media groups applied to the specimen. This addresses the third specific aim: Is there a difference in microleakage group means, measured as infiltration depth and area in micrometers, when comparing finish lines placed on Class V restorations made with different direct restorative materials (Tetric EvoCeram, Tetric EvoCeram Bulk Fill, Tetric EvoFlow and Fuji II LC) against different staining fluids (coffee, tea, red wine, and Coca-Cola) for adhesively bonded lithium disilicate crowns? Because there is not a statistically significant difference between the depth or area staining in the specimen, the third research hypothesis can be rejected (when comparing the microleakage depth and area, it is expected the treatment group subjected to the staining fluid of 'Coca-Cola' will have a statistically significant increase in microleakage depth and area when compared to the other treatment groups, including coffee, tea, and red wine, regardless of the type of direct restorative material used (Tetric EvoCeram, Tetric EvoCeram Bulk Fill, Tetric EvoFlow and Fuji II LC). The null hypothesis for the third research specific aim (there will be no difference in microleakage 
depth or area in comparing staining fluids among treatment groups) can be accepted. Coca-Cola did not have any more microleakage than the other staining fluids.

Table 5 depicts pairwise comparisons for the restorative material testing groups, including the positive controls. A Tukey's post-hoc analysis was performed and determined that there was a statistical significance between the treatment groups in terms of microleakage depth and area of penetration. The Tetric EvoFlow treatment groups were statistically significantly higher in staining fluid penetration depth and area when compared to the Tetric EvoCeram, Tetric EvoCeram Bulk Fill, and Fuji II LC treatment groups, in addition to the positive controls $(\mathrm{p}=0.00, \mathrm{p}<0.05)$. There was no statistically significant difference in staining fluid depth penetration when comparing the Tetric EvoCeram, Tetric EvoCeram Bulk Fill, Fuji II LC treatment groups, and the positive controls ( $p>0.05)$. This addresses the second specific aim for the project: Is there a difference in microleakage group means, measured as infiltration depth and area in micrometers, when comparing finish lines placed on Class $\mathrm{V}$ restorations made with different direct restorative materials (Tetric EvoCeram, Tetric EvoCeram Bulk Fill, Tetric EvoFlow and Fuji II LC) against treatment groups for adhesively bonded lithium disilicate crowns subjected to different staining fluids (coffee, tea, red wine, and CocaCola)? Because there is a statistically significant difference between the depth or area staining in the specimen comparatively across the treatment groups, the second research hypothesis can be accepted (when comparing the microleakage depth and area, it is expected the treatment group 'Tetric EvoFlow' (nano-hybrid flowable resin composite) will have a statistically significant increase in microleakage depth and area when compared to the other treatment groups, including Tetric EvoCeram (nano-hybrid resin 
composite), Tetric EvoCeram Bulk Fill (nano-hybrid bulk fill resin composite), and Fuji II LC (resin-modified glass ionomer)). The null hypothesis for the second research specific aim (there will be no difference in microleakage depth or area in comparing treatment groups) can be rejected. Tetric EvoFlow exhibited more microleakage than the other treatment groups. The clinician should consider using Tetric EvoCeram (nanohybrid resin composite), Tetric EvoCeram Bulk Fill (nano-hybrid bulk fill resin composite), or Fuji II LC (resin-modified glass ionomer) rather than Tetric EvoFlow (nano-hybrid flowable resin composite) for restoration longevity and decreased microleakage.

Table 5 also depicts microleakage depth and area across control groups and treatment groups. The control groups in each restorative material category were not statistically significant in microleakage depth and area when compared to treatment groups, with the exception of Tetric EvoFlow treatment groups $(\mathrm{p}=0.00, \mathrm{p}<0.05)$. In other words, any of Tetric EvoCeram, Tetric EvoCeram Bulk Fill, and Fuji II LC treatment groups permit statistically similar amounts of microleakage as dental tissues when affixed with an indirect restoration. This addresses the first specific aim for the project: Is there a difference in microleakage group means, measured as infiltration depth and area in micrometers, when comparing finish lines placed on Class $\mathrm{V}$ restorations made with different direct restorative materials (Tetric EvoCeram, Tetric EvoCeram Bulk Fill, Tetric EvoFlow and Fuji II LC) against a positive control for adhesively bonded lithium disilicate crowns subjected to different staining fluids (coffee, tea, red wine, and CocaCola)? Because there is not a statistically significant difference between the depth or area staining between the positive controls and the treatment groups with similar staining 
profiles, the first research hypothesis can be rejected: When comparing the microleakage depth and area, it is expected the treatment groups, including Tetric EvoFlow (nanohybrid flowable resin composite), Tetric EvoCeram (nano-hybrid resin composite), Tetric EvoCeram Bulk Fill (nano-hybrid bulk fill resin composite), and Fuji II LC (resinmodified glass ionomer) will have statistically significant increased microleakage depth and area when compared to the positive control. The null hypothesis for the first research specific aim (there will be no difference in microleakage depth or area in comparing treatment groups to the positive control) can be accepted. Within each specimen, the treatment group and the positive control exhibited similar microleakage staining fluid depth and area of penetration.

Figures 13-16 give graphical illustrations of mean microleakage values for the independent variables. Figure 13 gives microleakage depth in microns for the liquid media groups. Although Coca-Cold had the most microleakage depth when compared to coffee, red wine, and tea, none of the values were different enough from each other to be deemed statistically significant. Figure 14 gives the microleakage depth in microns for the restorative material groups. As can be seen in the figure, Tetric EvoFlow had a much larger amount of microleakage depth than the Tetric EvoCeram, Tetric EvoCeram Bulk Fill, and Fuji II LC treatment groups. This is statistically significant, as given in Table 5. Figure 15 gives microleakage area in microns for the liquid media groups. Again, although tea had the most microleakage when compared to coffee, Coca-Cola, and red wine, none of the values were different enough from each other to be deemed statistically significant. Figure 16 gives the microleakage area in microns for the restorative material groups. As can be seen in the figure, Tetric EvoFlow had a much larger amount of 
microleakage depth than the Tetric EvoCeram, Tetric EvoCeram Bulk Fill, and Fuji II LC treatment groups. This is statistically significant, as given in Table 5 .

The overall research hypothesis was: The degree of microleakage of four staining fluids (coffee, tea, Coca-Cola, and red wine) will be larger for Tetric EvoFlow (nanohybrid flowable resin composite) than Tetric EvoCeram (nano-hybrid resin composite), Tetric EvoCeram Bulk Fill (nano-hybrid bulk fill resin composite), or Fuji II LC (resinmodified glass ionomer) amongst thermocycled and loaded class $\mathrm{V}$ restorations in teeth with a resin composite/ceramic crown restorative margin, with Coca-Cola exhibiting the largest area and depth of microleakage overall. According to the results listed above, the Tetric EvoFlow (nano-hybrid flowable resin composite) did indeed have the largest amount of microleakage when compared to the other direct resin composites (Tetric EvoCeram (nano-hybrid resin composite), Tetric EvoCeram Bulk Fill (nano-hybrid bulk fill resin composite), or Fuji II LC (resin-modified glass ionomer)), but Coca-Cola did not exhibit the largest area and depth of microleakage overall, as there was not a significant difference between the staining fluid microleakage. More information about these results can be seen in the discussion. 


\section{DISCUSSION}

This research investigates the interface between a direct and an indirect restoration. When a researcher finishes an indirect restoration, such as a pressed lithium disilicate ceramic crown, on direct restorative materials, such as resin composite or resin-modified glass ionomer, there is increased chance for polymerization shrinkage, microgap formation, and subsequent microleakage staining around the margin of the restoration.

This in vitro research study used common staining fluids to test microleakage in the specimen. The microleakage penetration depth and area data collection design were based upon a prior pilot study conducted by the researchers, in which a $0.5 \%$ basic fuchsin dye tracer was used to test microleakage in both control and treatment groups consisting of interfaces between Class III and Class V restorations and lithium disilicate indirect restorations. This pilot study also used a cyclic uniaxial loader and thermocycler to simulate intraoral conditions, as well as multiple sectional averages and stereomicroscopy (50X) to view depth and area of penetration. The foundation behind this type of testing comes from literature, stating microleakage tests are more likely to yield accurate results if 'the cavities of third molars [have] a diameter of $3 \mathrm{~mm}$ and a depth of at least $1 \mathrm{~mm}$ and a sample size of at least 10 [and] multiple sectional averages of specimens on dye tracer penetration' are used $(39,40)$. This pilot study sites missing literature evaluations between microleakage at a resin cement/restorative material interface and dye penetration correlated to clinical results $(41,42)$. Because this research study builds upon this pilot 
study, similar methods of data collection were employed, and the literature discrepancies stated above are still applicable to this study. Furthermore, use of common beverages as staining fluids rather than a $0.5 \%$ basic fuchsin dye tracer has not been cited in the literature, and thus, there are not ISO standards for these results. The research team has standardized all samples to the best of their ability, and a 0.000 significance for Box's Test of Equality of Covariance Matrices indicates all samples were statistically consistent. It is the research team's opinion that this data is statistically accurate and clinically relevant.

The staining fluids were measured according to depth and area of penetration, which was viewed with a 50X magnification via stereomicroscopy. Microleakage occurred with equal statistical significance for most of the treatment groups (excluding Tetric EvoFlow) and the control groups. The control side of the tooth, consisting of a lithium disilicate indirect restoration luted to enamel/dentin tissue, resulted in microleakage between these two entities, or within the resin cement dental luting material layer. Staining largely occurred along the enamel near the cavosurface margin, most likely due to failure of the resin cement adhesive after it was subjected to shear force and changes in temperature through use of a cyclic uniaxial loader and a thermocycler. It is not unreasonable to suggest this staining along a cavosurface margin could occur intraorally, especially if the resin cement is subjected to a challenging oral environment.

The treatment sides of the tooth, consisting of a lithium disilicate indirect restoration luted to a direct restorative dental material, also resulted in microleakage between these two entities, or within the resin cement dental luting agent layer. For the Tetric EvoCeram, Tetric EvoCeram Bulk Fill, and the Fuji II LC treatment groups, there was 
not a statistically significant increase in staining depth or area when compared to the control. Most of the staining occurred along the direct restorative cavosurface margin, within the resin cement luting agent layer. The Tetric EvoFlow treatment group had a statistically significant increase in staining depth and area when compared to the control, with the staining occurring along the direct restorative cavosurface margin, within the resin cement luting agent.

The research team predicted a statistically significant increase in depth and area of staining between the control and treatment groups (specific aim 1), however, only the Tetric EvoFlow yielded this result. The research team has considered several explanations for this data. Although placement of an indirect restoration on an existing composite restoration should yield a poorer bond strength and more potential microleakage than a control, it is possible the specimen did not experience enough shear force or temperature changes through the thermocycler to accurately simulate these results. Alternatively, the thermocycler cycles have the potential to wash out some of the dye penetration. In future studies, it may be important to complete data collection without a thermocycler. Further explanations include the sample environment. An in vitro environment does not subject specimen to biofilm, enzymes, or other oral conditions. It is possible the bonding strength was artificially increased in the samples. Within the staining fluids themselves (Coca-Cola, coffee, tea, and red wine instead of the $0.5 \%$ basic fuchsin dye tracer), staining could differ. If the beverages did not exhibit the same staining potential as the fuchsin dye, the results could have had decreased staining depth and area penetration across all the samples, resulting in a false negative statistical significance. The research team has considered performing a study in which the staining 
fluids and the fuchsin dye are directly compared in order to test accuracy in results.

The Tetric EvoFlow treatment groups had a statistically significant increase in staining depth and area when compared to all other groups, including the control, Tetric EvoCeram, Tetric EvoCeram Bulk Fill, and Fuji II LC. This result was expected by the research team, as evident from specific aim 2. A possible explanation for this lies in the properties of flowable composite, itself. The resin cement used in this study is a selfetching dual-cure luting agent, which was not able to create a hybridized bond to the flowable composite. Furthermore, any polymerization shrinkage within the flowable composite created a porous, permeable interface for the staining fluids to access. This result is clinically significant for the study. A flowable composite system, such as Tetric EvoFlow, has the potential for increased microleakage, especially in clinical situations subjected to shear force. A clinician should be meticulous when choosing direct restorative materials for patients who might have contraindications to crown lengthening and indications for fixed dental prostheses at a later time, especially when it comes to flowable composite materials.

It is important to note that in this study, each direct restoration was completed with the segmental/cross-hatch technique and increments of $2 \mathrm{~mm}$ or less. If a clinician is using a bulk fill resin composite and curing increments of up to $4 \mathrm{~mm}$ at a time, there is the potential for uncured resin composite in the deeper portions of the restoration. If any bulk fill composite is left uncured, there is a greater potential for microleakage in the future. Although this study yielded statistically insignificant results between the Tetric EvoCeram and the Tetric EvoCeram Bulk Fill, the research team recognizes the potential for problems with this material if used incorrectly. 
Although there is not a cited systematic review with respect to common staining fluids and the interface between resin cement and direct restorative materials, this study suggests higher penetration and potential for microleakage when a flowable resin composite is used as the margin of an indirect restoration as compared to other direct restorative materials. This higher penetration is likely due to high polymerization shrinkage and lower filler content within the material, resulting in a weaker seal between the dental tissue and the direct restorative material. An increase in microleakage along the margin of a fixed dental prostheses could lead to a compromised clinical outcome, whether due to staining, secondary caries, or pulpal post-operative sensitivity. Although these findings occurred in an in vitro study, and results could vary in an intraoral environment, clinicians should understand limitations dental materials, namely flowable resin composite materials as finish lines for indirect restorations. 


\section{CONCLUSION}

On a fundamental level, this study attempts to give a good recommendation for the most ideal composite restoration material to use when faced with a clinical situation which requires indirect restoration longevity on teeth with existing direct restorations and

contraindications to crown lengthening or subgingival finish lines. Regardless of staining beverages a patient may consume, whether coffee, tea, red wine, or sodas such as CocaCola, the clinician should consider using nano-hybrid resin composite, nano-hybrid bulk fill resin composite, or resin-modified glass ionomer rather than nano-hybrid flowable resin composite for restoration longevity and decreased microleakage. 


\section{REFERENCES}

1. Baroudi K, Rodrigues JC. Flowable Resin Composites: A Systematic Review and Clinical Considerations. J Clin Diagn Res. 2015;9(6):ZE18-24.

2. Lendenmann, Urs. Wanner, Marion. Scientific Documentation Tetric EvoCeram ${ }^{\circledR / T e t r i c ~ E v o F l o w ® . ~ I v o c l a r ~ V i v a d e n t ~ A G ~ R e s e a r c h ~ \& ~ D e v e l o p m e n t . ~}$ 2011 Feb;No Vol, No Issue:1-33.

3. Bayne SC. A characterization of first-generation flowable composites. Journal of American Dental Association. 1998;129:567-77

4. Nuray, Attar N, Tam LE, McComb D. Flow, strength, stiffness and radiopacity of flowable resin composites. J Can Dent Assoc. 2003 Sept;69(8):516-21.

5. Burke FJ, Wilson NH, Cheung SW, Mjör IA. Influence of patient factors on age of restorations at failure and reasons for their placement and replacement. J Dent. 2001 July; 29(5):317-24.

6. Toshiki, Takamizawa T, Yamamoto A, Inoue N, Tsujimoto A, Oto T, Irokawa A, Tsubota K, Miyazaki M. Influence of light intensity on contraction stress of flowable resins. J Oral Sci. 2008 Mar; 50(1):37-43.

7. Lokhande1, Niket A. Padmai, Amit S. Rathore, Vishnu Pratap Singh. Shingane, Shrikant. Jayashankar, D N. Sharma, Usha. Effectiveness of Flowable Resin Composite in Reducing Microleakage - An In Vitro Study. Journal of International Oral Health. 2014;6(3):111-114.

8. Ferracane JL. Models of Caries Formation Around Dental Composite Restorations. J Dent Res. 2016;96(4):364-371.

9. Li Y, Carrera C, Chen R, Li J, Lenton P, Rudney JD, Jones RS, Aparicio C, Fok A. Degradation in the dentin-composite interface subjected to multi-species biofilm challenges. Acta Biomater. 2014 Jan; 10(1):375-83.

10. Nedeljkovic I, Teughels W, De Munck J, Van Meerbeek B, Van Landuyt K.L. Is secondary caries with composites a material-based problem? Dent Mater. 2015 Nov; 31(11): e247-e277

11. Soares CJ, Faria-E-Silva AL, Rodrigues MP, Vilela ABF, Pfeifer CS, Tantbirojn D, Versluis A. Polymerization shrinkage stress of composite resins and resin cements - What do we need to know?. Braz Oral Res. 2017 Aug 28;31:e62.

12. Roberson T, Heymann H, Swift E. Sturdevant's Art and Science of Operative Dentistry. Rev ed 5. St. Louis, MO: Mosby, Inc; 2006. 
13. Ivoclar Vivadent Inc. Tetric EvoCeram ${ }^{\circledR}$ Universal Nano-Hybrid Composite: Package Inserts. https://www.ivoclarvivadent.us/explore/tetric-evoceram. 2019. Accessed Jan 2019.

14. Fugolin APP, Pfeifer CS. New Resins for Dental Composites. J Dent Res. 2017 Sep; 96(10): 1085-1091.

15. Jang JH, Park SH, Hwang IN. Polymerization shrinkage and depth of cure of bulk fill resin composites and highly filled flowable resin. Oper Dent. 2015;40(2):172-180.

16. Ivoclar Vivadent Inc. Tetric EvoCeram ${ }^{\circledR}$ Bulk Fill. http://www.ivoclarvivadent.com/en/p/all/products/restorativematerials/composites/tetric-evoceram-bulk-fill. 2019. Accessed Nov 2018.

17. Chesterman JJ. Bulk Fill Resin-Based Composite Restorative Materials: A Review. British Dental Journal. 2017 Mar;222(5):337-344.

18. Sidhu SK, Nicholson JW. A Review of Glass-Ionomer Cements for Clinical Dentistry. J Funct Biomater. 2016;7(3):16. Published 2016 Jun 28.

19. GC America. GC Fuji II LC® Light-Cured, Resin-Reinforced Restorative. http://www.gcamerica.com/products/operatory/GC_Fuji_II_LC/. 2019. Accessed Jan 2019.

20. Schwendicke FF. Directly Placed Restorative Materials: Review and Network Meta-analysis. Journal of Dental Research. 2016 Jun;95(6):613-22.

21. Sofan E, Sofan A, Palaia G, Tenore G, Romeo U, Migliau G. Classification Review of Dental Adhesive Systems: From the IV Generation to the Universal Type. Ann Stomatol (Roma). 2017 Jan-Mar; 8(1): 1-17.

22. Weiland Dental, A Company of Ivoclar Vivadent Group. 3 Shape D1000 Scanner. http://www.wieland-dental.de/en/products/zenotec/scanner/3shape-d1000/. 2019. Accessed March 2018.

23. Tsirogiannis P, Reissmann D, Heydecke G. Evaluation of the marginal fit of single-unit, complete-coverage ceramic restorations fabricated after digital and conventional impressions: A systematic review and meta-analysis. J Prosthet Dent. 2016 Sep; 116(3): 328-335.

24. Homsy FR, Özcan M, Khoury M, Majzoub ZAK. Marginal and internal fit of pressed lithium disilicate inlays fabricated with milling, 3D printing, and conventional technologies. J Prosthet Dent. 2018;119:783-790.

25. H.J. Conrad, W.J. Seong, I.J. Pesun. Current ceramic materials and systems with clinical recommendations: a systematic review. J Prosthet Dent. 2007; 98:389404.

26. Culp L, McLaren EA. Lithium disilicate: the restorative material of multiple options. Compend Contin Educ Dent. 2010 Nov-Dec;31(9):716-20, 722, 724-5. 
27. Pieger S, Salman A, Bidra AS. Clinical outcomes of lithium disilicate single crowns and partial fixed dental prostheses: a systematic review. J Prosthet Dent. 2014 Jul; 112(1): 22-30.

28. Contrepois, Mathieu et al. Marginal adaptation of ceramic crowns: A systematic review. Journal of Prosthetic Dentistry. 2013 Oct;110(6):447-454.

29. Lad PP, et. al. Practical clinical considerations of luting cements: A review. Journal of international oral health. 2014;6(1):116-20.

30. Ivoclar Vivadent Inc. Multilink Automix. http://www.ivoclarvivadent.com/en/p/all/products/luting-material/adhesive-lutingcomposite/multilink-automix. 2019. Accessed Jan 2019.

31. Tian T, Tsoi JKH, Matinlinna JP, Burrow MF. Aspects of bonding between resin luting cements and glass ceramic materials. Dental Materials. 2014;30(7):147162.

32. Matinlinna JP, Lung CYK, Tsoi JKH. Silane adhesion mechanism in dental applications and surface treatments: A review. Dental Materials. 2018;34(1):1328.

33. El-Damanhoury HM, Gaintantzopoulou MD. Self-etching ceramic primer versus hydrofluoric acid etching: Etching efficacy and bonding performance. Journal of Prosthodontic Research. 2018;62(1):75-83.

34. Instron®. Illinois Tool Works Inc. Shear Adhesion Strength Testing Dental Materials and Adhesives. http://www.instron.us/en-us/testing-solutions/by-testtype/shear/dental-materials-and-adhesives. 2019. Accessed March 2018.

35. Instron®. Illinois Tool Works Inc. Shear Strength. http://www.instron.us/enus/our-company/library/glossary/s/shear-strength. 2019. Accessed March 2018.

36. LAM Technologies electronic equipment LTC100. http://www.dentalequipment.it/Resources/Documentation/LTC100_BRUK.pdf. Jan 2006. Accessed March 2018.

37. Nothnagle PE, Chambers W, Davidson MW. Nikon® MicroscopyU: The Source for Microscopic Education.

https://www.microscopyu.com/techniques/stereomicroscopy/introduction-tostereomicroscopy. 2019. Accessed March 2018.

38. Accuscope®. Support/FAQ’s. http://accu-scope.com/support/frequently-askedquestions/. 2019. Accessed March 2018.

39. ISO. Dental materials - testing of adhesion to tooth structure. Technical Specification; 2003 [No. 11405].

40. Raskin A, Tassery H, D’Hoore W, Gonthier S, Vreven J, Degrange M, et al. Influence of the number of sections on reliability of in vitro microleakage evaluations. American Journal of Dentistry. 2003;16:207-10. 
41. Heintze SD. Clinical relevance of tests on bond strength, microleakage and marginal adaptation. Dent Mater. 2013 Jan;29(1):59-84.

42. Mohan S, Pushpa K, Patil BC, Satheesh HB. Evaluation of microleakage in hybrid composite restoration with different intermediate layers and curing cycles. Journal of Dental and Allied Sciences. 2016;5(1):14-20. 


\section{APPENDIX}

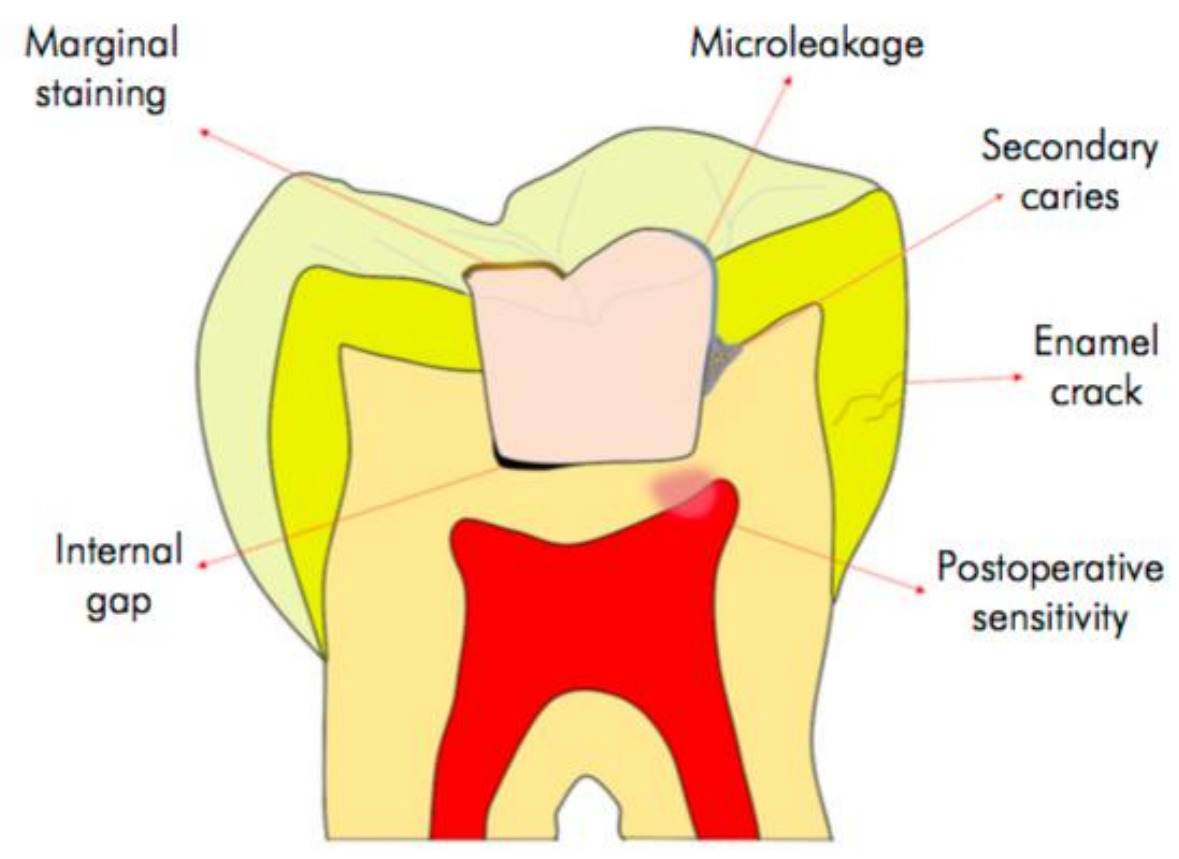

Appendix Figure 1. Schematic signs and symptoms caused by polymerization shrinkage (11). 


\section{CURRICULUM VITA}

NAME:

ADDRESS:

EDUCATION

\& TRAINING:

Sarah Jestel

The University of Louisville School of Dentistry

501 S Preston Street

Louisville, KY 40202

University of Louisville School of Dentistry

Expected Graduation Date, May 2019:

D.M.D. (Doctor of Dental Medicine)

M.S. (Master of Science, Oral Biology)

Academic Dental Careers Fellowship Program (Certificate)

University of Georgia

B.S. in Chemistry, Dec. 2014

PROFESSIONAL SOCIETIES:

\section{American Dental Education Association at ULSD}

Chair, August 2018 to May 2019

Serving as the ULSD representative on ADEA Council of Students, Residents, and Fellows.

Coordinate and preside over executive board and member meetings

Encourage inclusion of allied professionals through dental hygiene mentorship events.

Developed the annual chapter budget and secured $\$ 4,000$ in conference travel funds.

Represented the chapter at annual session, Chicago, IL and presented student research.

Vice Chair, August 2017 to May 2018

Oversaw student committees within the chapter.

Collaborated with other ADEA chapters' executive boards at monthly regional meetings.

Achieved 'Gold Level Chapter' status at the 2018 national convention for chapter involvement.

Achieved 'Recognition for Inclusion of Allied Health Professionals' national award in 2018.

Represented ULSD as a COSRF delegate at annual session, Long Beach, CA.

Represented the chapter at fall session conference, Columbus, $\mathrm{OH}$. 
American Student Dental Association at ULSD

Member, July 2015 to May 2019

Omicron Kappa Upsilon Nu Chapter

Member, inducted April 2019

National Dental Honor Society for fourth-year dental students.

Delphi Society Alpha Chapter

Member, inducted in Spring 2018

ULSD's Honorary Dental Society for the top $15 \%$ of students in each third-year class.

Phi Beta Kappa

Member, inducted Spring 2015

National Honor Society for undergraduate students

RESEARCH

PRESENTATIONS: Research! Louisville

2016 - Marginal Staining Between Pressed Lithium Disilicate Ceramic Crowns and Direct Restorative Materials: A Microleakage Study

2017 - Marginal Staining Between Pressed Lithium Disilicate Ceramic Crowns and Direct Restorative Materials by Various Fluids: A Microleakage Study

2018 - Using Aesthetic Case-Based Learning to Help Students Improve Conceptual Knowledge and Clinical Application

ADEA Annual Session, Chicago, IL

$\underline{2019}$ - Academic Dental Careers and Fellowship Program Poster Presentations: Using Aesthetic Case-Based Learning to Help Students Improve Conceptual Knowledge and Clinical Application

2019 - Student Research Poster Presentations: Using Aesthetic Case-Based Learning to Help Students Improve Conceptual Knowledge and Clinical Application

DENTAL

EXPERIENCE: $\quad$ Red Bird Mission, Eastern Kentucky

Student clinician in September 2017 and July 2018

Provided extensive restorative and surgical dental care to a lower income patient population.

Performed oral health screenings for 50 patients, students, and drug rehabilitation participants.

Chosen student representative to speak at the Red Bird Mission reception in September of 2018. 